\title{
Características papeleiras dos bambus do Estado do Acre
}

\author{
Antôniø de Azevedo Corrêa (") \\ Cláudio Nazareno Reis Luz (") \\ Francisco Juvenal Lima Frazäo (")
}

\begin{abstract}
Resumo
Uma amostra de bambus do Estado do Acre foi estudada sob o ponto de vista de celulose e papel. Neste trabalho apresenta-se informaçōes sucintas sobre a distribuiçāo geográfica desta gramínea e sua utilização pela indústria papeleira, especialmente no continente asiático. Características gerais sobre o solo, clima e relevo são em seguida evidenciados. Avaliaçōes sobre a densidade, classificação e micrometria das fibras, qualidades das pastas químicas, semiquimicas, mecano-químicas, e mecânicas, assim como resultados dos alvejamentos, clareamentos e do cálculo da potencialidade de utilização são mostrados. Concluindo-se qui os bambus do Acre são factíveis de serem utilizados na fabricação de pasta especialmente destinadas a manufaturas de papel de embalagem.
\end{abstract}

\section{INTRODUÇÃo}

A Amazônia é particularmente rica em celulose de fibra curta em decorrência do seu elevado potencial de madeiras folhosas e no que concerne a matéria de fibra longa é menos favorecida; entretanto, pesquisas recontes, efetuadas pelo Projeto "RADAM" (1), mostraram uma larga ocorrência de bambu no Estado do Acre. A avaliação das características desta matéria-prima, apresentamos neste trabalho.

\section{DISTRIBUIÇÃO GEOGRÁFICA DOS BAMBUS}

O bambu é uma gramínea alta de origem principalmente tropical que cresce especialmente em bosque monçônico. Devido a esta característica, sua maior ocorrência se verifica no continente asiático, onde aparece espontâneamente cobrindo superfícies na India, Pa- quistão, Japão, Taywan, Indonésia, Camboja, Vietnã, Tailândia e Birmânia. Na India existem cerca de 800.000 hectares estimados de bambus, 500.000 dos quais são acessiveis e estão em exploração. No Japão a ocorrência é de 160.000 hectares e em Taywan 48.000. $\mathrm{Na}$ Birmânia existem aproximadamente $9 \mathrm{mi}$ thōes de hectares de bambus, que poderiam sustentar uma colheita anual de 45 milhōes de toneladas (Wayman, 1973). Entre os gêneros mais freqüentes encontrados nos povoamentos de bambus na Ásia, podem ser citados os seguintes como mais importantes: Bambusa Dendrocalamus, Phyllostachys, Arundi e Ocheandras (Doat, 1967).

$\mathrm{Na}$ Africa existem duas espécies de bambus espontâneos: Arundinaria alpina e Oxytenanthera abyssinica e outras espécies que foram introduzidas (Ibid).

A Arundinaria alpina é encontrada nas montanhas da Africa Oriental, na República dos Camarões entre 2.000 a $3.400 \mathrm{~m}$ de altitude, em clima úmido (pluviosidade de 1,800 a $3.000 \mathrm{~mm}$ ), sobre solos argilosos ou vulcânicos. Em altitudes elevadas as zonas de povoamento puros são muito abrangentes (vários milhares de hectares na Kenya). A baixa altitude os bambus se encontram associados com floresta de folhosas ou de resinosos (lbid).

A Oxytenanthera abyssinica se encontra em povoamentos gregários cobrindo algumas vezes grandes superficies em condiçöes ecológicas extremamente variada de 0 à $2.000 \mathrm{~m}$ de altitude, de 700 à $2.000 \mathrm{~mm}$ de pluviosida. de com estação seca de 3 à 7 meses, desenvolvendo-se em tudos os tipos de solos com

(1) - O Projeto RADAMBRASIL tem por meta primordial mapear e avaliar recursos naturais, em escala regional e a relativo curto prazo, a fim de que alcançados esses objetivos as regiöes mais promissoras sob o ponto de vista de suas potencialidades naturais sejam submetidas a estudos mais detalhados. (Projeto RADAMBRASIL - 1976).

(*) - Instituto Nacional de Pesquisas da Amazônia, Manaus. 
exceção de terrenos salinos e argilosos pesados. Este tipo de bambu é o mais resistente a seca. Encontra-se sobre as encostas inferiores dos maciços montanhosos e em planície particularmente na Guiné, Senegal, Etiópia, Zaire, Zâmbia, Sudão, República Centro Africana e Moçambique. As hastes raramente ultrapassam $10 \mathrm{~m}$ de altura e $5 \mathrm{~cm}$ de diâmetro sendo freqüentemente retas. O estabelecimento não é definitivo e são factiveis em determinadas condições a regressões temporárias (lbid). Bambusa vulgaris chamado "Bambu da China" foi introduzido em vários países africanos, onde se tornou subespontâneo. Suas exigências ecológicas são extremamente variáveis, adaptando-se aos mais diversos climas e numerosos tipos de solcs. Encontra-se em zonas de floresta densa, bem como em savanas úmidas a baixa altitude até $1.000 \mathrm{~m}$ e cresce em tufos fechados (lbid).

No continente americano, o gênero Guadua é o mais importante; Guadua angustiofolia na Colômbia e Equador, Guadua amplexifolia desde o norte da Venezuela até a Nicarágua e Honduras, Guadua inermes no México e Guadua superba no Brasil. Em maiores altitudes e em climas temperados da América Latina o gênero Chusque é o mais freqüente. Na América do Norte existem somente duas espécies nativas: Arundinaria gigantea e Arundinaria tecta (Huberman, 1959).

$\mathrm{Na}$ Amazônia os bambus que são conhecido com a denominação local de "Tabocas" ocorrem pelo menos em dois gêneros: Guadua e Nastus. Paul Le Cointe (1947) assim os relaciona:

Taboca - Guadua angustifolia, Guadua glomerata, Guadua morim, aparecendio especialmente na llha de Marajó.

Taboca da folha larga - Nastus amazonicus, existindo principalmente no Alto Purus.

Taboca Grande, Taboca Gigants, Taquaruçu - Guadua superba que cresce em terras altas dos Estados do Amazonas e Acre.
UTILIZAÇÃO DO BAMBU PELA INDÚSTRIA DE CELULOSE E PAPEL

O bambu é utilizado desde os primórdios pela indústria papeleira. Constituiu fonte de matéria-prima das antigas fábricas artezanais da China e do Japão (Doat, 1967).

$\mathrm{Na}$ atualidade sua maior utilização encontra-se na Ásia, principalmente na India e na China. Entretanto, existem fábricas na Birmânia, Filipinas, Japão, Paquistão, República do Khamer e Tailândia (Wayman, 1973). Na India a participação do bambu é de $70 \%$ em relação a todos os materiais fibrosos utilizados por aquele país na obtenção de pasta a papel (Doat, 1967).

Doat (Ibid), relaciona as seguintes unidades de fabricação em vários países asiáticos que utilizam o bambu, como fonte de matéria-prima (Quadro I).

Como se observa, o que caracterizam essas unidades são os seus pequenos portes operarem em integração vertical, até a produção de papel e seus produtos serem consumidos no mercado local (Doat, 1967).

No Brasil, a participação das pastas provenientes de bambu é ainda muito baixa em comparação com as pastas fabricadas de madeiras (Ver Quadro II) e somente cinco fábricas (2) de pequenas dimensões manufaturam esta matéria-prima na obtenção de celulose.

AMOSTRA DE BAMBU ESTUdAdA PELA SEÇÃo DE CELULOSE E PAPEL DO INPA

A amostra estudada correspondeu a 100 $\mathrm{kg}$ de bambu, coletada no Estado do Acre (cf. mapa), onde esta gramínea ocorre em associação com a floresta tropical em proporções variáveis de $20 \%$ a $80 \%$ em uma área estimada de $85.000 \mathrm{~km}^{2}$, sobre solos férteis como o podzólico vermelho-amarelo, eutrófico e epieutrófico, apresentando argila de atividade alta e texurura argilosa, em relevo que varia do suave ondulado a forte ondulado. O clima da área

(2) - Companhia Mineira de Papéis - 4.500 t/ano - Celulose sulfato branqueada - Estado de Minas Gerais Companhia Fabricadora de Papeis Itajai - 60 t/ano - Celulose sulfato crua - Estado de Santa Catarina. Companhia Industrial Brasileira Portela - 2.300 t/ ano - Celulose sulfato crua - Estado de Pernambuco. Indústria de Papéis Santo Amaro S/A. - 9.000 t/ ano - Celulose soda crua - Estado da Bahia. Companhia de Papel e Papeläo Pedras Brancas - 1.400 t/ano de pastas semiquímicas a soda (Associaçăo Paulista dos Fabricantes de Papel e Celulose). 
na classificaçăo "Köppen" é do tipo Am-tropical chuvoso, com temperaturas médias anuais de $24,5^{\circ} \mathrm{C}$, máximas de $32^{\circ} \mathrm{C}$ e mínimas de $18^{\circ} \mathrm{C}$, apresentando variações locais em função da maior ou menor exposição aos sistemas atmosféricos extra-tropicais. Freqüentemente a região é atingida pelo fenômeno da "friagem" que resulta do avanço da frente polar, impulsionada pela massa de ar polar, provocando brusca queda na temperatura, permanecendo alguns dias com.médias eın torno de $10^{\circ} \mathrm{C}$. A pluviosidade apresenta totais anuais médios aproximados de $1.800 / 2.000 \mathrm{~m} . \mathrm{m}$. e no trimestre mais seco a média não atinge $125 \mathrm{~mm}$ (RADAM-BRASIL).
CLASSIFTCAÇÃO, CARACTERÍSTICAS MICROMÉTRICAS DAS FIBRAS E DENSIDADE DO BAMBU

Das pastas provenientes dos cozimentos soda-enxofre, efetuou-se a classificação dos comprimentos segundo o procedimento TAPPI - T233 - SU - 64 em Classificador de Fibras "Clark", modelo M-46. Das partes retidas em cada compartimento, realizou-se mensurações em Projetor Olympus $-4 \mathrm{P}-360$

As larguras das fibras e das cavidades foram dimensionadas em microscópio monocular E. Leitz, com lente ocular 10X, objetiva $43 \mathrm{X}$ e fator 3,14 .

\section{QUADRO I}

Exemplos de fábricas que utilizam bambu na Ásia

\begin{tabular}{|c|c|c|c|}
\hline País & Nome da Sociedade & Tipo de cozimento & Quantidade fabricada por ano \\
\hline fndia & Bengal Paper Mills & Sulfato & $\begin{array}{l}14.000 \text { Ton. de papel de impressão } \\
\text { escrever }\end{array}$ \\
\hline Indis & fndia Paper Pulp Co. & Bissulfito de Magnésio & 6. 500 Ton. de Papel \\
\hline India & Sirpur Paper Mills & Sulfato & 15.000 Ton. de Papel \\
\hline India & The Titaghur Paper Mills & Sulfato & $\begin{array}{l}42.000 \text { Ton. de papel impressão } \\
\text { escrever, embalagem e cartão. }\end{array}$ \\
\hline India & The Ballapur Paper Mills & Sulfato & $\begin{array}{l}8.000 \text { Ton. de papel impressão, } \\
\text { offset, duplicata. }\end{array}$ \\
\hline India & The Mysore Paper Mills & Kraft & $\begin{array}{l}\text { 8.000 Ton. de papel de impressão. } \\
\text { escrever. }\end{array}$ \\
\hline fndia & $\begin{array}{l}\text { The National Newsprint } \\
\text { and Paper Mills Nepana. } \\
\text { gar }\end{array}$ & $\begin{array}{l}\text { Sulfato de Bambu e Pas- } \\
\text { ta Mecânica de Folhosas }\end{array}$ & 20.00 Ton. \\
\hline fndia & Orient Paper Mills & Sulfato & $\begin{array}{l}36.000 \text { Ton de papel de impressão, } \\
\text { embalagem, crepom, cartão, diver- } \\
\text { sos... }\end{array}$ \\
\hline Paquistāo & Karnaphuli Paper Mills & Sulfato & $\begin{array}{l}30.000 \text { Ton. de papel de impressão } \\
\text { escrever e diversos. }\end{array}$ \\
\hline Tailândia & Kanchanaburi & $\begin{aligned} \text { Kraft } 80 \% & \text { Bambu } \\
20 \% & \text { Bombax }\end{aligned}$ & 3.000 Ton. \\
\hline$\underset{n}{\text { Camboja }}$ & Usina de Chlong & Sulfato & 8.000 Ton. \\
\hline Indonésia & State Paper Mill Goa & Sulfato & 9.000 Ton. \\
\hline
\end{tabular}

FONTE: Doat, 1967: 41-59. 


\section{QUADRO II}

Produção brasileira de pastas químicas e semiquí. micas, segundo a matéria-prima utilizada, em t, 1975

\begin{tabular}{lrrrrr}
\hline $\begin{array}{c}\text { Matéria- } \\
\text { prima }\end{array}$ & $\begin{array}{c}\text { Pasta } \\
\text { química }\end{array}$ & $\begin{array}{c}\text { Pasta semi- } \\
\text { química }\end{array}$ & Total & $\%$ \\
\hline Eucalipto & 740422 & 28513 & 768935 & 64,66 \\
Pinheiro & 321967 & 4852 & 326819 & 27,47 \\
Bambu & 15930 & 1542 & 17472 & 1,47 \\
Outros & 27802 & 48580 & 76382 & 6,42 \\
TOTAL & 1.106121 & 83487 & 1189608 & 100,00
\end{tabular}

FONTE: Associaçāo Paudista dos Fabricantes de Papel e Celulose. Relatório Estatístico, 1975.

A densidade foi determinada sobre os cavacos pelo método $\mathrm{RC}-91-$ TAPPI.

Os resultados destes ensaios estão consignados na tabela $n .{ }^{\circ} 1$.

Em que concerne as características morfológicas, os bambus do Acre apresentam fibras que em relação ao comprimento se individualizam por serem superiores às folhosas, mas inferiores aos resinosos.

As fibras são relativamente estreitas e suas cavidades sendo pequenas, fazem com que as mesmas apresentem suas paredes bastante espessas.

O coeficiente de flexibilidade situa-se abaixo dos encontrados nos resinosos e na faixa do apresentado pelas folhosas. É comparável aos bambus africanos, especialmente ao bambu do Senegal (Doat, 1967). Os valores apresentados permite esperar que os papéis fabricados das pastas provenientes dos bambus da região do Acre, apresentem uma boa resistência à auto-ruptura, dobras-duplas, e ao estouro.

$\mathrm{O}$ índice de feltragem é superior aos verificados nos angiospermas e nos geminospermas utilizados pela indústria de celulose. tipificando fibras propícias para a confecção de papéis resistentes e que exijam uma porosidade elevada.

Considerando a importância para a avaliação da qualidade de uma pasta do peso médio dos comprimentos das fibras (Clark, 1962), calculou-se este parâmetro para as fibras das pastas do bambu através da fórmula:

$L=\frac{W_{1} L_{1}+W_{2} L_{2}+W_{3} L_{3}+W_{4} L_{4}+W_{5} L_{5}}{W}$

Onde:

$\mathrm{L}=$ Peso médio do comprimento da fibra.

$\left(L_{1}, L_{2}, L_{3}, L_{4}\right)=$ Comprimento das fibras nos diversos compartimentos do classificador.

$W_{5}=$ Peso da amostra calculado por diferença.

$\mathrm{W}=$ Peso inicial da amostra.

O resultadc obtido foi de uma ordem de grandeza de $2,252 \mathrm{~mm}$.

TABELA N.॰ I - Classificação, características micrométricas das fibras e densidade do bambu

\begin{tabular}{|c|c|c|c|c|c|}
\hline \multirow{2}{*}{ CARACTERISTICAS } & \multicolumn{5}{|c|}{ COMPARTIMENTOS } \\
\hline & N. 1 & N. 2 & N. 3 & N. ${ }^{4}$ & N. 5 \\
\hline Comprimento das fibras ( $\mathrm{Mu})$-L- valores médios & 3.600 & 2.206 & 1.290 & 995 & 580 \\
\hline Largura das fibras (Mu)-1- valores médios & 19 & 14 & 14 & 12 & \\
\hline Largura das cavidades ( $\mathrm{Mu}$ )-C- valores médios & 9 & 7 & 6 & 6 & \\
\hline Coeficiente de flexibilidade $\mathrm{C} / 1$ & 47 & 50 & 43 & 50 & \\
\hline fndice feltrante $\mathrm{L} / 1$ & 189 & 157 & 92 & 83 & \\
\hline$\%$ retirada em cada compartimento & 40 & 23 & 10 & 3 & 24 \\
\hline Densidade * & & & 0,64 & & \\
\hline
\end{tabular}

Valor calculado segundo Método Toppi -T-232 - SU - 68. 
A densidade do bambu situou-se na mesma faixa dos bambus africanos que variam de 0,40 à 0,80 , sendo superior a densidade dos resinosos e das folhosas que tradicionalmente são manufaturadas pelas indústrias de pasta a papel. Entretanto, isto não chega a constituir um inconveniente, uma vez que os bambus utilizados principalmente pela indústria indiana, apresentam densidade correlata à observada no bambu do Acre.

\section{COMPOSIÇÃO QUÍMICA DO BAMBU}

As análises químicas do bambu foram efetuadas segundo as normas do TAPPI (3) e $A B C P$ (4).

Os resultados das análises químicas do bambu estão contidos na tabela $n$. II.

Como se observa, em relação as solubilidades os valores apresentados foram relativamente elevados. Considerando a soma dos extrativos em água e soda $1 \%$, verifica-se que o seu valor foi próximo de $25 \%$. Isto explica, segundo (Doat, 1967) a aptidão dos bambus fornecerem a $100^{\circ} \mathrm{C}$ e a pressão atmosférica em meio alcalino, pastas duras porém desfibráveis, susceptíveis de serem utilizadas em certos tipos de fabricaçōes de papéis tais como: cartão ou ondulado.

Verifica-se que o teor em álcool-benzol é bastante elevado, assemelhando-se aos bambus africanos e cujo valor igualou-se ao bambu do Gabão (Ibid.), sendo, no entanto, inferiores aos resinosos introduzidos na Amazô- nia (Corrêa \& Luz, 1976) e situando-se ao redor dos valores apresentados pelo Eucalyptus saligna (Mazzei \& Overbeck, 1966).

A quantidade de lignina aproxima-se das cifras encontradas nos resinosos, enquanto que o teor de pentosanas é da mesma ordem que os verificados nas folhosas e inferiores aos encontrados nas palhas (Doat, 1967).

$\mathrm{O}$ teor de celulose se enquadrou na faixa dos resultados das folhosas e das palhas e foi inferior aos resinosos.

Em relação ao teor de cinzas, o valor encontrado foi da ordem de $3,0 \%$, sendo comparável aos apresentados pelos bambus pesquisados em diferentes laboratórios (Doat, 1967; Mazzei \& Redko, 1967; Tissot, 1970; Redko, \& Nishimura, 1972).

O teor de cinzas do bambu do Acre foi superior aos das folhosas e resinosos e muito inferiores aos das palhas (lbid.). As cinzas do bambu possuem uma particularidade de conter uma grande quantidade de síiica, constituindo-se na principal dificuldade encontrada na utilização industrial desta matéria-prima. Tissot (1970) ao analisar este inconveniente na indústria indiana, verificou que a sílica causava um maior desgaste nas facas dos picadores do que os normalmente encontrados nas folhosas. Isto era agravado pelo esforço que as facas faziam nas picagens das hastes, por serem os bambus revestidos por uma película muito resistente.

A despeito de algumas soluções práticas utilizadas pelas indústrias indianas (5) para

TABELA N.॰ II - Composição química do bambu da região do Estado do Acre

\begin{tabular}{c|c|c|c|c|c|c|c|c}
\hline $\begin{array}{c}\text { Sol. em } \\
\text { Agua Fria } \\
\text { \$ }\end{array}$ & $\begin{array}{c}\text { Sol. em } \\
\text { Agua } \\
\text { Quente } \\
\%\end{array}$ & $\begin{array}{c}\text { Na01. em } \\
\%\end{array}$ & $\begin{array}{c}\text { Sol. em } \\
\text { Alcool- } \\
\text {-Benzol } \\
\%\end{array}$ & $\begin{array}{c}\text { Lignina } \\
\%\end{array}$ & $\begin{array}{c}\text { Pentosanas } \\
\%\end{array}$ & $\begin{array}{c}\text { Celulose } \\
\text { Bruta } \\
\%\end{array}$ & $\begin{array}{c}\text { Celulose } \\
\text { Corrigida } \\
\%\end{array}$ & $\begin{array}{c}\text { Cinzas } \\
\%\end{array}$ \\
\hline 2,8 & 3,5 & 21,5 & 2,0 & 27,0 & 18,0 & 44,6 & 43,0 & 3,0 \\
\hline
\end{tabular}

(3) - Technical Association of the Pulp and Paper Industry.

(4) - Associação Técnica Brasileira de Celulose e Papel.

( 5 ) - "Central Pulp Mills, Limited", situada próxima à cidade de Fort Songad, Estado de Gujarat. Esta fábrica utilizava o método de "esmagamento", que consistia em passar as hastes dos bambus entre dois cilindros canelados e após a picagem, os cavacos eram la vados em correntes de água.

- "National Newsprint and Paper Mills Ltd". (Nepa Mill) à Nepanagar, Estado de Madhya Pradesh, situada na estrada de ferro que liga Bombay à Nova Delhi a cerca de $500 \mathrm{~km}$ a nordeste de Bombay. Antes da picagem, esta fábrica efetuava somente uma lavagem superficial nas hastes.

- "Bengal Paper Mill Co. Ltd". à Raniganj, distrito de Burdwan, Bengala Ocidental. Esta fábrica mergulha os cavacos em uma bacia, antes da picagem. 
favorecer a picagem das hastes dos bambus e eliminar uma parte da sílica superficial. algumas toneladas deste material eram introduzidas no circuito de fabricação, causando efeitos indesejáveis em todas as etapas do tratamento para a obtençäo da celulose, a qual apresentava um pequeno teor de sílica (menos que $1 \%$ ). A ação nefasta da silica se verificava ao se depositar em forma de escamas sobre os tubos dos evaporadores, chegando a constituir cerca de $25 \%$. Igualmente a sílica se depositava sobre os tubos da caldeira de recuperaçăo e nas paredes do forno de cal em forma de lupa vitrificada, causando um baixo rendimento das instalações de recuperação e uma má qualidade do cal reciclado.

A solução encontrada pela indústria indiana para superar estes inconvenientes, foram de duas ordens: 1 - Não utilizando a lama de cal, eliminando assim uma parte da sílica; 2 - Injetando nos evaporadores ao nivel do $3 .^{\circ}$ efeito uma solução de soda à $150 \mathrm{~g} / 1$ de maneira a elevar $\mathrm{o} \mathrm{pH}$ do licor. $\mathrm{O} \mathrm{pH}$ entre $10,0-10,5$, proporcionava o desaparecimento das escamas nos evaporadores.

OBTENÇÃo DE PASTAS CELULÓSICAS DOS BAMBUS

Para obtenção das pastas celulósicas, os bambus foram transformados manualmente em cavacos, nas seguintes dimensões $7,0 \times 0,6 \times 0,4 \mathrm{~cm}$, e uma série de ensaios de fabricação foi realizada visando a obtenção de pasta química e pasta de alto rendimento.

OBTENÇÃo DE PASTA QUímica "KRAFT"

Duas séries de cozimentos foram efetuados pelo procedimento Soda/Enxofre (variante do processo "Kraft") a $155^{\circ} \mathrm{C}$ e a $170^{\circ} \mathrm{C}$ em cozinhador rotativo de 10 litros, aquecimento elétrico e 1 r.p.m.

As condiçōes retidas para a efetivação dos cozimentos foram as seguintes:

\begin{tabular}{l|c|c}
\hline \multicolumn{1}{c|}{ Condições } & $\mathbf{1 7 0 ^ { \circ } \mathbf { C }}$ & $\mathbf{1 5 5} \mathbf{C}$ \\
\hline $\begin{array}{l}\text { Na OH/Mad. } \\
\text { Seca }\end{array}$ & $18 \% 22 \% 26 \%$ & $18 \% 22 \% 26 \%$ \\
$\begin{array}{l}\text { Enxofre/Mad. } \\
\text { Seca }\end{array}$ & $1,8 \% 2,2 \% 2,6 \%$ & $1,8 \% 2,2 \% 2,6 \%$ \\
$\begin{array}{l}\text { Diluição } \\
\begin{array}{l}\text { Tempo à Temp. } \\
\text { de Patamar }\end{array}\end{array}$ \\
$\begin{array}{l}\text { Tempo na Temp. } \\
\text { de Patamar }\end{array}$ & $3,3: 1$ & $3,3: 1$ \\
\end{tabular}

As pastas obtidas dos cozimentos foram desintegradas logo após a degasagem em "Pulper" de laboratório "Allibe" (tendo-se antes retirado uma amostra do licor negro para a determinação do álcali residual), lavadas, depuradas em depurador Brecht Holl, (peneira $0,6 \mathrm{~mm}$ ) e desaguada até a uma consistência de $30 \%$ em centrífuga S.A. 30 AW 2, Rousselet a 1500 r.p.m., determinando-se em seguida os rendimentos brutos e depurados, rejeitos sobre a madeira seca, alvura das pastas e índices de permanganatos.

Os resultados obtidos dos cozimentos "Tipo-Kraft" do bambu apresentamos na tabela n. III.

No ponto de vista prático estes resultados significam que os bambus do Estado do Acre não são difíceis de serem tratados pelo procedimento Soda/Enxofre. A um nível de $22 \%$ de $\mathrm{NaOH} /$ Madeira seca já se obtém pastas bem deslignificadas sem taxa de rejeito proibitivo.

Os $\mathrm{N}^{\circ} \mathrm{s}$. de $\mathrm{KMnO}_{4}$ dos tratamentos a $170^{\circ} \mathrm{C}$ foram ligeiramente inferiores aos verificados para o tratamento a $155^{\circ} \mathrm{C}$. Observa-se que a $18 \%$ de $\mathrm{NaOH} /$ Madeira seca, o índice de deslignificação apresenta-se baixo, caracterizando pastas relativamente "duras" para ambos os tratamentos. 
Os rendimentos foram baixos quando comparados com os apresentados pelos bambus africanos e asiáticos, porém equivalentes aos verificados para o Bambusa vulgaris schrad (Doat, 1967; Tissot, 1970 e Azzini, 1976).

Entre os tratamentos, os rendimentos apresentados pelos cozimentos a $155^{\circ} \mathrm{C}$ com 3 horas de duração foram superiores aos da série $170^{\circ} \mathrm{C}$ com 1 hora e 30 minutos.

As percentagens de $\mathrm{NaOH}$ residual foram superiores nos cozimentos a $155^{\circ} \mathrm{C}$ e cresceram em ambos os tratamentos em função da quantidade de $\mathrm{NaOH}$ introduzido.

\section{PASTA QUÍMICA À SODA}

A mesma metodologia empregada para obtenção de pasta pelo processo tipo "Kraft", foi aplicada para se conseguir pasta pelo tratamento à soda. Foram realizados dois en- saios de cocçōes com 2 horas de montagem e 1 hora e 30 minutos de patamar a temperatura de $170^{\circ} \mathrm{C}$.

Os resultados dos cozimentos à soda do bambu podem serem vistos na Tabela n. IV.

As pastas químicas obtidas pelo processo à soda, são mais duras do que as produzidas pelo processo soda/enxofre.

Os rendimentos das pastas à soda se situaram na mesma escala dos apresentados pelas pastas Kraft, nas mesmas condições de tratamento.

As percentagens de $\mathrm{NaOH}$ residual foram superiores as verificadas nos tratamentos soda/enxofre, em decorrência da ação deslignificante do $\mathrm{Na}_{2} \mathrm{~S}$ formado no decorrer da cocção Kraft.

Comparando os dois tratamentos, nota-se que com a exceção da alvura (as pastas à so-

TABELA N. III - Resultados dos cozimentos soda/enxofre do bambu do Estado do Acre.

\begin{tabular}{|c|c|c|c|c|c|c|c|c|}
\hline \multirow{2}{*}{$\begin{array}{l}\text { Número } \\
\text { dos } \\
\text { cozimentos }\end{array}$} & \multirow{2}{*}{ Patamar } & \multirow{2}{*}{$\begin{array}{c}\mathrm{NaOH} \\
\%\end{array}$} & \multirow{2}{*}{$\begin{array}{l}\mathbf{S} \\
\%\end{array}$} & \multirow{2}{*}{$\begin{array}{c}\text { fndice } \\
\text { de } \\
\mathrm{KMnO}_{4}\end{array}$} & \multicolumn{2}{|c|}{ Rendimento } & \multirow{2}{*}{$\begin{array}{c}\mathrm{NaOH} \\
\mathrm{g} / \mathbf{1}\end{array}$} & \multirow{2}{*}{$\begin{array}{c}\text { "Photovolt" } \\
\text { (alvura da } \\
\text { pasta) }\end{array}$} \\
\hline & & & & & $\begin{array}{c}\text { Bruto } \\
\%\end{array}$ & $\begin{array}{c}\text { Depurado } \\
\%\end{array}$ & & \\
\hline 300 & & 18 & 1,8 & 22 & 39,5 & 39,5 & 1,8 & 39 \\
\hline 298 & $1 \mathrm{~h} 30^{\prime}-170^{\circ} \mathrm{C}$ & 22 & 2,2 & 18 & 38,1 & 38,1 & 3,2 & 46 \\
\hline 296 & & 26 & 2,6 & 11 & 37,3 & 37,3 & 4,0 & 48 \\
\hline 304 & & 18 & 1,8 & 27 & 44,5 & 44,5 & 2,0 & 42 \\
\hline 303 & $3 \mathrm{~h}-155^{\circ} \mathrm{C}$ & 22 & 2,2 & 16 & 41,4 & 41,4 & 4,8 & 47 \\
\hline 302 & & 26 & 2,6 & 13 & 40,5 & 40,5 & 8,8 & 49 \\
\hline
\end{tabular}

TABELA N. IV - Resultados dos cozimentos à soda do bambu do Estado do Acre

\begin{tabular}{|c|c|c|c|c|c|c|c|}
\hline \multirow{2}{*}{$\begin{array}{l}\text { Número } \\
\text { dos cozi- } \\
\text { mentos }\end{array}$} & \multirow{2}{*}{ Patamar } & \multirow{2}{*}{$\begin{array}{c}\mathrm{NaOH} \\
\%\end{array}$} & \multirow{2}{*}{$\begin{array}{l}\text { fndice } \\
\text { de } \\
\mathrm{KMnO}_{4}\end{array}$} & \multicolumn{2}{|c|}{ Rendimento } & \multirow{2}{*}{$\begin{array}{c}\mathrm{NaOH} \\
\mathrm{g} / 1\end{array}$} & \multirow{2}{*}{$\begin{array}{c}\text { "Photovolt" } \\
\text { alvura da } \\
\text { pasta }\end{array}$} \\
\hline & & & & $\begin{array}{c}\text { Bruto } \\
\%\end{array}$ & $\begin{array}{c}\text { Depurado } \\
\%\end{array}$ & & \\
\hline 305 & $1 \mathrm{~h} 30^{\prime}-1700 \mathrm{C}$ & 22 & 24 & 37 & 37 & 6,0 & 54 \\
\hline 306 & & 18 & 33 & 39 & 39 & 1,0 & 48 \\
\hline
\end{tabular}


da apresentam maior Photovolt), o processo à soda não apresenta vantagem significativa na obtenção de pasta química.

\section{ALVEJAMENTOS DAS PASTAS QUÍMICAS DO BAMBU}

As pastas cruas obtidas dos cozimentos Soda/Enxofre e à Soda do bambu foram alvejadas pelos processos C.E.H.H. e C.E.D.P.D.

Os resultados estão consignados nas tabelas $n^{\circ}$ s. V, VI, VII e VIII.
Como se verifica, o maior consumo de reagentes para ambos os alvejamentos corresponderam para as pastas que apresentaram um índice de deslignificação mais baixo, isto é, cujos $n^{\circ}$ s. de $\mathrm{KMnO}_{4}$ foram superiores a 19.

Comparando os consumos de reagentes observa-se que as pastas dos cozimentos à Soda demandaram uma maior percentagem de alvejantes tanto no procedimento C.E.H.H. como no C.E.D.P.D. Em contra-partida as pastas

TABELA N: V - Resultados dos alvejamentos (Cl $-\mathrm{NaOH}-\mathrm{ClONa}-\mathrm{ClONa})$ - das pastas cruas dos cozimentos soda/en:ofre do bambu

\begin{tabular}{|c|c|c|c|c|c|c|c|c|c|}
\hline \multirow{2}{*}{$\begin{array}{c}\text { Cozi- } \\
\text { mento } \\
\mathrm{N} .0\end{array}$} & \multirow{2}{*}{$\begin{array}{c}\text { Cloração } \\
\text { cloro } \\
\text { consu- } \\
\text { mido } \\
\%\end{array}$} & \multicolumn{2}{|c|}{ Sodação } & \multicolumn{2}{|c|}{ 1." fase: ClONa } & \multicolumn{2}{|c|}{ 2.A fase: ClONa } & \multirow{2}{*}{$\begin{array}{c}\text { "Photovolt" } \\
\text { alvura da } \\
\text { pasta }\end{array}$} & \multirow[b]{2}{*}{$\begin{array}{l}\text { Estabilidade } \\
\text { da alvura }\end{array}$} \\
\hline & & $\begin{array}{c}\mathrm{NaOH} \\
\text { int. } \\
\%\end{array}$ & $\begin{array}{c}\mathrm{NaOH} \\
\text { cons. } \\
\%\end{array}$ & $\begin{array}{l}\text { Cloro } \\
\text { int. } \\
\%\end{array}$ & $\begin{array}{c}\text { Cloro } \\
\text { cons. } \\
\%\end{array}$ & $\begin{array}{l}\text { Cloro } \\
\text { int. } \\
\%\end{array}$ & $\begin{array}{c}\text { Cloro } \\
\text { cons. } \\
\%\end{array}$ & & \\
\hline 300 & 0,5 & 4,0 & 3,4 & 4,0 & 2,9 & 0,5 & 0,2 & 85 & 77 \\
\hline 298 & 0,3 & 4,0 & 3,3 & 4,0 & 2,5 & 0,5 & 0,2 & 85 & 78 \\
\hline 296 & 0,3 & 4,0 & 3,0 & 4,0 & 2,5 & 0,5 & 0,2 & 86 & 80 \\
\hline 304 & 0,4 & 4,0 & 3,4 & 4,0 & 3,0 & 0,5 & 0,2 & 88 & 78 \\
\hline 303 & 0,3 & 4,0 & 3,2 & 4,0 & 2,6 & 0,5 & 0,2 & 86 & 79 \\
\hline 302 & 0,3 & 4,0 & 3,2 & 4,0 & 2,5 & 0,5 & 0,2 & 88 & 81 \\
\hline
\end{tabular}

TABELA N. VI - Resultados dos alvejamentos Cl- $\left(\mathrm{NaOH}-\mathrm{H}_{2} \mathrm{O}_{2}\right) \cdot \mathrm{ClO}_{2}-\mathrm{H}_{2} \mathrm{O}_{2} \cdot \mathrm{ClO}_{2} \mid$ das pastas cruas dos cozimentos soda/enxofre do bambu

\begin{tabular}{|c|c|c|c|c|c|c|c|c|c|c|c|c|c|}
\hline \multirow{2}{*}{$\begin{array}{c}\text { Cozimento } \\
\text { N.D }\end{array}$} & \multirow{2}{*}{$\begin{array}{c}\text { Cloraçăo } \\
\text { eloro } \\
\text { consumido } \\
\%\end{array}$} & \multicolumn{4}{|c|}{ SODAÇĀO OXIDANTE } & \multicolumn{2}{|c|}{ 3." fose: $\mathrm{ClO}_{2}$} & \multicolumn{2}{|c|}{4.8 fase: $\mathrm{H}_{2} \mathrm{O}_{2}$} & \multicolumn{2}{|c|}{ 5.8 fose: $\mathrm{ClO}_{2}$} & \multirow{2}{*}{$\begin{array}{l}\text { "Photo- } \\
\text { volt" } \\
\text { alvura } \\
\text { da posta }\end{array}$} & \multirow[b]{2}{*}{$\begin{array}{l}\text { Estabilida } \\
\text { dade da } \\
\text { alvura }\end{array}$} \\
\hline & & $\begin{array}{l}\mathrm{NoOH} \\
\text { int. } \\
\%\end{array}$ & $\begin{array}{l}\text { NaOH } \\
\text { eons. } \\
\%\end{array}$ & $\begin{array}{l}\mathrm{H}_{3} \mathrm{O} \text {, } \\
\text { int. } \\
\%\end{array}$ & $\begin{array}{l}\mathrm{H}_{3} \mathrm{O} \text { ? } \\
\text { cons. } \\
\%\end{array}$ & $\begin{array}{l}\text { Cloro } \\
\text { int. } \\
\%\end{array}$ & $\begin{array}{l}\text { Cloro } \\
\text { cons. } \\
\%\end{array}$ & $\begin{array}{l}\mathrm{H}_{2} \mathrm{O}_{2} \\
\text { int? } \\
\%\end{array}$ & $\begin{array}{l}\mathrm{H}_{3} \mathrm{O} \text { ? } \\
\text { cons. } \\
\%\end{array}$ & $\begin{array}{l}\text { Cloro } \\
\text { Int. } \\
\%\end{array}$ & $\begin{array}{l}\text { Cloro } \\
\text { cons. } \\
\%\end{array}$ & & \\
\hline 300 & 0,5 & 4,0 & 3,6 & 1,0 & 1,0 & 2,6 & 2,3 & 1,0 & 0,9 & 1,3 & 0,9 & 93 & 86 \\
\hline 298 & 0,3 & 4,0 & 3,4 & 1,0 & 1,0 & 2,6 & 2,2 & 1,0 & 0,9 & 1,3 & 0,9 & 91 & 87 \\
\hline 296 & 0,3 & 4,0 & 3,3 & 1,0 & 1,0 & 2,6 & 2,2 & 1,0 & 0,9 & 1,3 & 0,9 & 90 & 85 \\
\hline 304 & 0,4 & 4,0 & 3,5 & 1,0 & 1,0 & 2,6 & 2,3 & 1,0 & 0,9 & 1,3 & 1,0 & 95 & 88 \\
\hline 303 & 0,3 & 4,0 & 3,4 & 1,0 & 1,0 & 2,6 & 2,1 & 1,0 & 0,9 & 1,3 & 1,0 & 94 & 88 \\
\hline 302 & 0,3 & 4,0 & 3,3 & 1,0 & 1,0 & 2,6 & 1,9 & 1,0 & 0,9 & 1,3 & 0,9 & 91 & 86 \\
\hline
\end{tabular}


TABELA N. VII - Resuitados dos alvejamentos (Cl-Na0H - Cl0Na - Cl0Na) das pastas cruas dos cozimentos à soda do bambu.

\begin{tabular}{|c|c|c|c|c|c|c|c|c|c|}
\hline \multirow{2}{*}{$\begin{array}{l}\text { Cozi- } \\
\text { mento } \\
\text { N.e }\end{array}$} & \multirow{2}{*}{$\begin{array}{c}\text { Cloração } \\
\text { Cloro } \\
\text { consu- } \\
\text { mido } \\
\%\end{array}$} & \multicolumn{2}{|c|}{ Sodação } & \multicolumn{2}{|c|}{ 1. fase: CloNa } & \multicolumn{2}{|c|}{ 2." fase: CloNa } & \multirow{2}{*}{$\begin{array}{c}\text { "Photovolt" } \\
\text { alvura da } \\
\text { pasta }\end{array}$} & \multirow{2}{*}{$\begin{array}{c}\text { Estabilidade } \\
\text { da } \\
\text { alvura }\end{array}$} \\
\hline & & $\begin{array}{c}\mathrm{Na} 0 \mathrm{H} \\
\text { int. } \\
\%\end{array}$ & $\begin{array}{l}\mathrm{NaOH} \\
\text { cons. } \\
\%\end{array}$ & $\begin{array}{c}\text { Cloro } \\
\text { int. } \\
\%\end{array}$ & $\begin{array}{c}\text { Cloro } \\
\text { cons. } \\
\%\end{array}$ & $\begin{array}{c}\text { Cloro } \\
\text { int. } \\
\%\end{array}$ & $\begin{array}{c}\text { Cloro } \\
\text { cons. } \\
\%\end{array}$ & & \\
\hline 305 & 0,5 & 4,0 & 3,1 & 4,0 & 2,2 & 0,5 & 0,1 & 93 & 85 \\
\hline 306 & 1,0 & 4,0 & 3,7 & 4,0 & 2,8 & 0,5 & 0,1 & 90 & 84 \\
\hline
\end{tabular}

TABELA N. VIII - Resultados dos alvejamentos $\left|\mathrm{Cl} \cdot\left(\mathrm{Na} 0 \mathrm{H} \cdot \mathrm{H}_{2} \mathrm{O}_{2}\right)-\mathrm{ClO}_{2}-\mathrm{H}_{2} \mathrm{O}_{2}-\mathrm{ClO}_{2}\right|$ das pastas cruas dos cozimentos à soda do bambu

\begin{tabular}{|c|c|c|c|c|c|c|c|c|c|c|c|c|c|}
\hline \multirow[b]{2}{*}{$\begin{array}{c}\text { Coximento } \\
\text { N.0 }\end{array}$} & \multirow{2}{*}{$\begin{array}{c}\text { Cloraşáo } \\
\text { cloro } \\
\text { consumido } \\
\%\end{array}$} & \multicolumn{4}{|c|}{ SODAÇĀO OXIDANTE } & \multicolumn{2}{|c|}{ 3. A fase: $\mathrm{ClO}_{2}$} & \multicolumn{2}{|c|}{ 4." fose: $\mathrm{H}_{2} \mathrm{O}_{2}$} & \multicolumn{2}{|c|}{ 3.2 fase: $\mathrm{ClO}_{2}$} & \multirow{2}{*}{$\begin{array}{l}\text { "Photo- } \\
\text { volt" } \\
\text { altura } \\
\text { da pasto }\end{array}$} & \multirow{2}{*}{$\begin{array}{c}\text { Estabitida- } \\
\text { de da } \\
\text { alvura }\end{array}$} \\
\hline & & $\begin{array}{c}\mathrm{NaOH} \\
\text { int. } \\
\%\end{array}$ & $\begin{array}{l}\mathrm{NoOH} \\
\text { cons. } \\
\%\end{array}$ & $\begin{array}{l}\mathrm{H}_{2} \mathrm{O}_{2} \\
\text { int. } \\
\%\end{array}$ & $\begin{array}{l}\mathrm{H}_{2} \mathrm{O}_{2} \\
\text { cons. } \\
\%\end{array}$ & $\begin{array}{l}\text { Cloro } \\
\text { int. } \\
\%\end{array}$ & $\begin{array}{c}\text { Cloro } \\
\text { cons. } \\
\%\end{array}$ & $\begin{array}{l}\mathrm{H}_{2} \mathrm{O}_{2} \\
\text { int. } \\
\%\end{array}$ & $\begin{array}{l}\mathrm{H}_{2} \mathrm{O}_{2} \\
\text { cons. } \\
\%\end{array}$ & $\begin{array}{l}\text { Cloro } \\
\text { int. } \\
\%\end{array}$ & $\begin{array}{l}\text { Cloro } \\
\text { cons } \\
\%\end{array}$ & & \\
\hline 305 & 1,7 & 4,0 & 3,8 & 1,0 & 1,0 & 2,6 & 2.3 & 1,0 & 0,9 & 1,3 & 1,0 & 95 & 89 \\
\hline 306 & 3,6 & 4,0 & 3,7 & 1,0 & 1,0 & 2,6 & 2,3 & 1,0 & 0,9 & 1,3 & 1,1 & 93 & 89 \\
\hline
\end{tabular}

à Soda apresentaram melhores alvuras e maiores estabilidades para o processo C.E.D.P.D.

Analisando os resultados apresentados pelos tratamentos C.E.H.H. e C.E.D.P.D. verificouse que tanto para as pastas provenientes dos cozimentos à Soda como as obtidas pelo processo Soda/Enxofre, o procedimento C.E.D.P.D. apresentou uma nitida vantagem subre o tratamento C.E.H.H., em decorrência de serem os bióxidos de cloro e os peróxidos, reativos mais seletivos à lignina, proporcionando melhores ganhos em alvura e maiores estabilidades.

Pelos resultados observados, as pastas químicas obtidas do bambu do Estado do Acre são factiveis de serem alvejadas pelos processos C.E.H.H. e C.E.D.P.D. e as alvuras apresentadas săo comparáveis e algumas vezes superiores aos das pastas branqueadas de folhosas e resinosas normalmente comercializadas no Brasil.
REFINOS DAS PASTAS QUÍMICAS

As pastas cruas dos cozimentos Soda/Enxofre foram refinadas em moinhos "Jokro", "Bauer" e "Holandesa". As pastas alvejadas provenientes do mesmo tratamento sofreram engrossamento nos equipamentos "Jokro" e "Bauer", enquanto que as pastas cruas e alvejadas do tratamento à Soda sofreram a ação de refinagem em moinho "Bauer".

Metodologicamente, as condições de refino tanto para as pastas cruas e alvejadas nos três equipamentos, assim foram conduzidas:

"Jokro" - $16 \mathrm{~g}$ de pasta seca, levada a uma consistência de $6 \%$, com cinco pontos de refino, dos quais o primeiro o ponto zero (pas. ta bruta), cobrindo uma escala de ${ }^{\circ} \mathrm{SR}$, que foi de $11^{\circ} \mathrm{SR}$ até $63^{\circ} \mathrm{SR}$.

"Bauer" - $16 \mathrm{~g}$ de pasta seca, a uma concentração de $0,2 \%$ submetidas a uma potên- 
cia de refino de $3,72 \mathrm{KW}$ com circulação forçada e área de contacto de 38 divisões no equipamento. Foram realizadas passagens sucessivas (o máximo três), até atingir o grau de engrossamento desejado.

"Holandesa" - $200 \mathrm{~g}$ de pasta seca com uma consistência de $1 \%$. A massa foi inicialmente desintegrada no próprio equipamento (operação realizada com os discos separados) por 30 minutos, adicionando-se em seguida a carga correspondente a $7.735 \mathrm{~g}$. unindo-se em seguida os discos. Quatro pontos de refino foram obtidos por período de 35 minutos.

Como se observa pelos gráficos de $n^{\circ} s$. I. II, III, IV, V, VI, VII e VIII as pastas químicas dos bambus do Estado do Acre refinam-se sem dificuldades.

As pastas cruas dos cozimentos Soda/Enxofre são mais gordas, apresentando uma maior facilidade de serem refinadas.

Comparando o tempo de refino gasto pelas pastas cruas provenientes dos cozimentos Soda/Enxofre a $155^{\circ} \mathrm{C}$ e a $170^{\circ} \mathrm{C}$ em relação ao percentual de $\mathrm{NaOH} /$ Madeira seca introduzido, verificou-se que as pastas fabricadas com o menor percentual de álcali demandaram um menor tempo para atingir um grau de engorda superior a $45^{\circ} \mathrm{SR}$. Esta ocorrência que poderia constituir uma anomalia, está talvez rela-

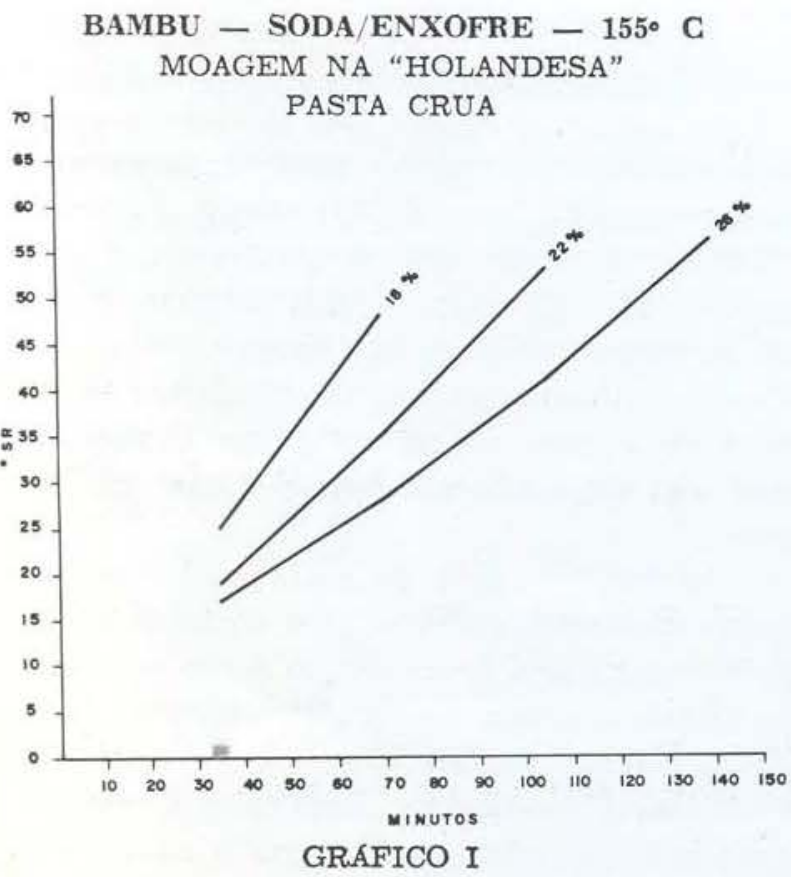

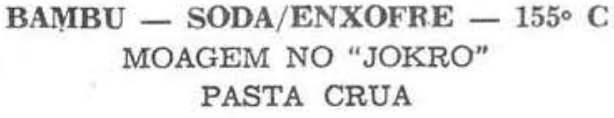

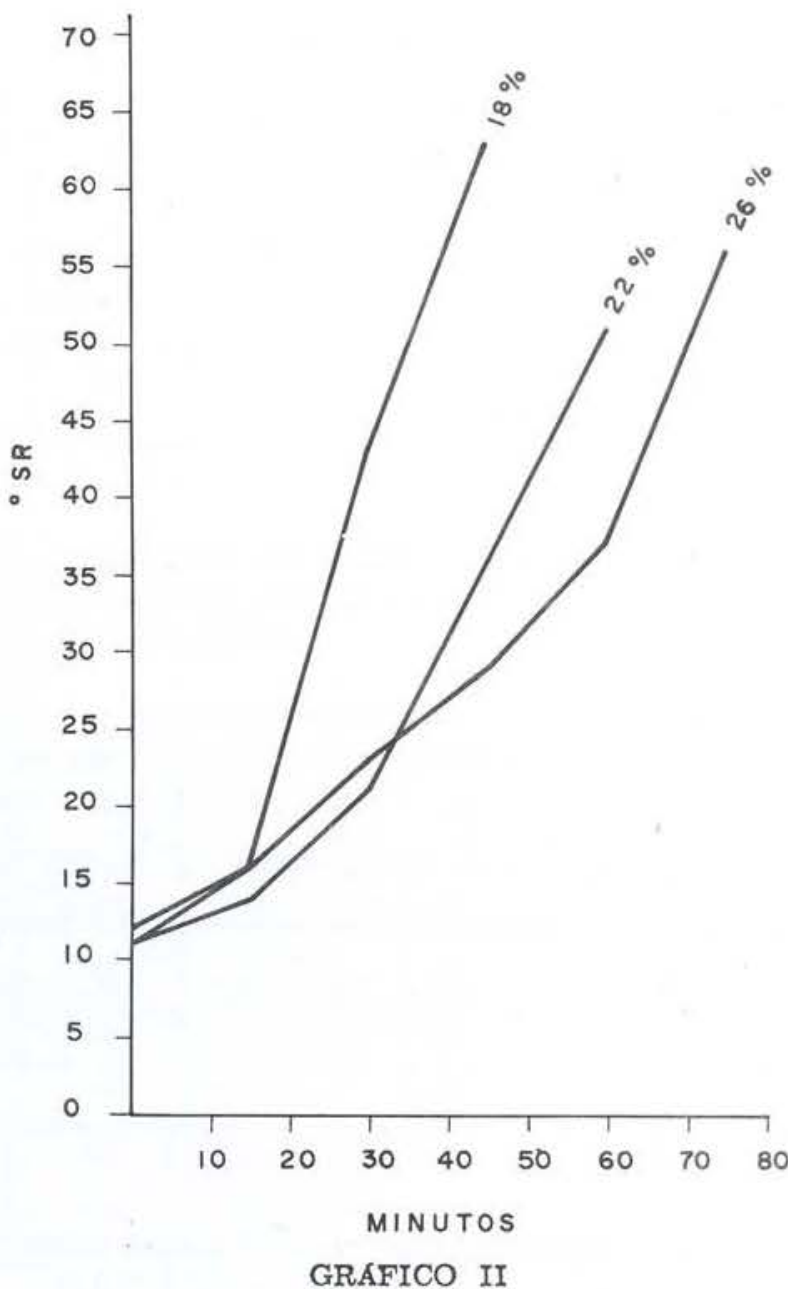

cionada com o teor remanescente de hemi-celuloses, que nas pastas fabricadas com um percentual menor de álcali, poderia ser superior aos das pastas obtidas com quantidades maiores de $\mathrm{NaOH} /$ Madeira seca. Esta hipótese é confirmada no refino das pastas alvejadas cujos graus de engorda foram conseguidos para as pastas cruas fabricadas com maiores proporções de reagentes. Considerando a ação dos agentes químicos dos alvejamentos os quais não somente atacaram as hemi-celuloses restantes nas pastas cruas obtidas ao nivel de $18 \%$ de $\mathrm{NaOH}$, como também causaram efeitos degradativos maiores nas cadeias celulósicas das pastas cruas conseguidas com maiores teores de álcali, tornando as pastas fabricadas aos níveis de $22 \%$ e $26 \%$ de $\mathrm{NaOH}$ mais aptas a ação dos refinos. 

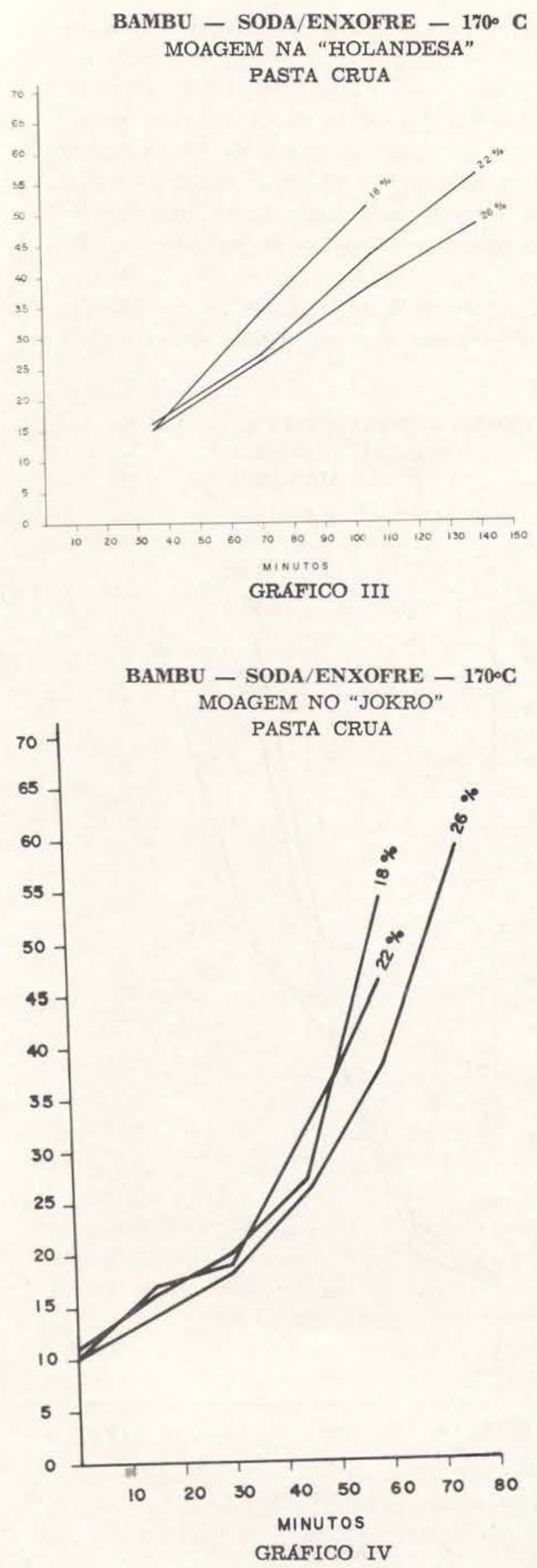

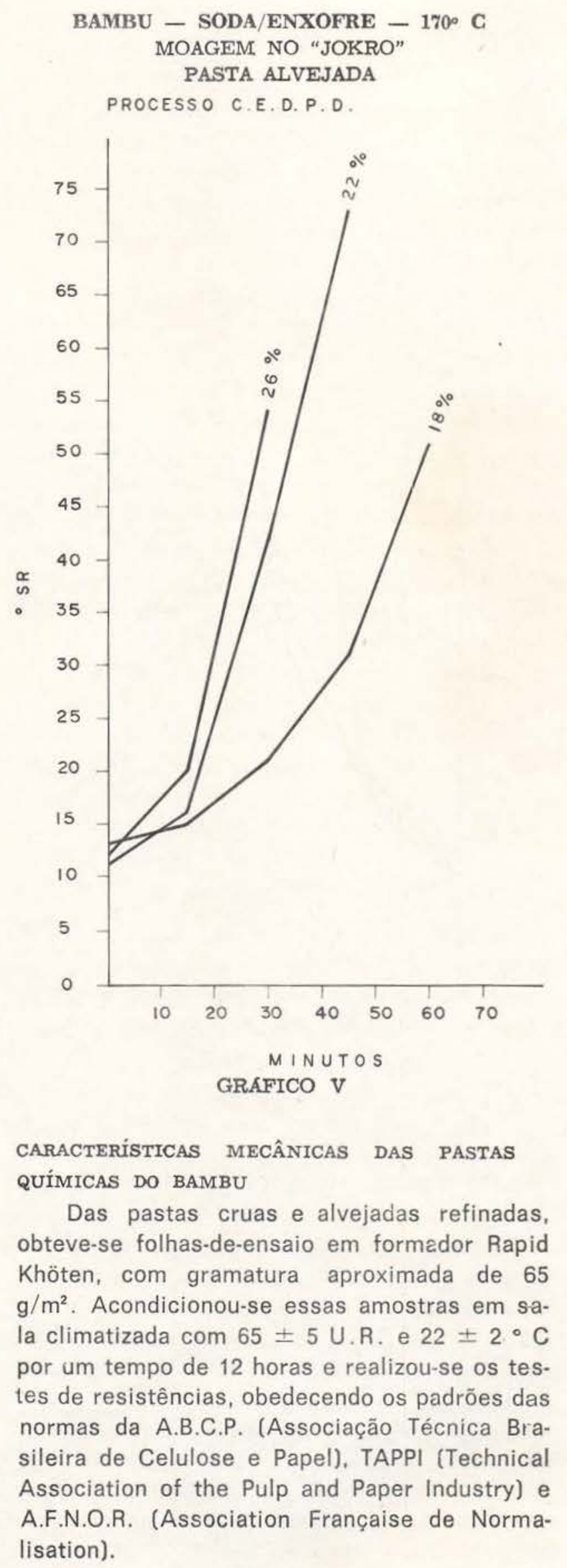




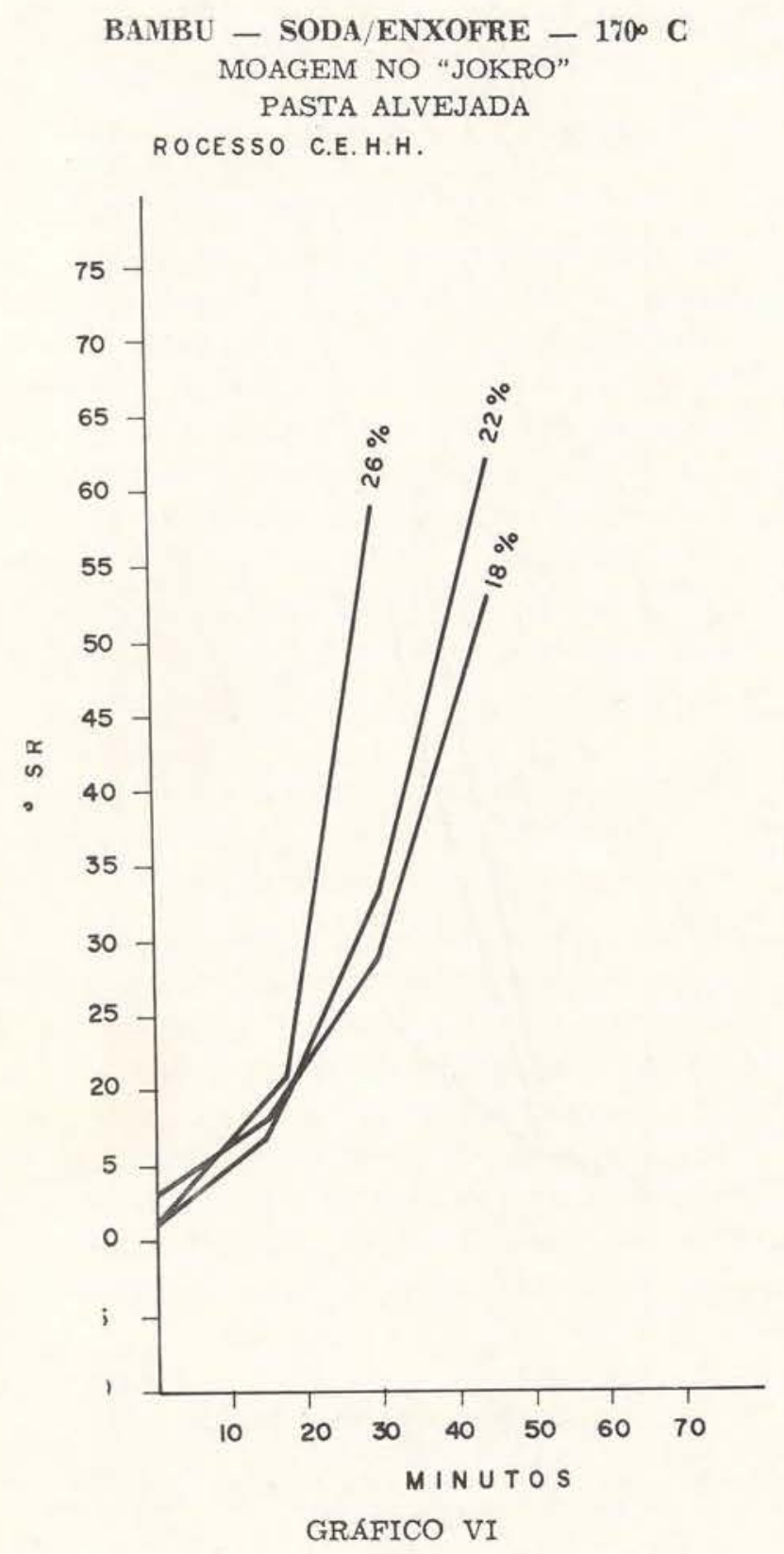

Os resultados obtidos são demonstrados nas tabelas n's. IX, X, XI e XII.

As características mecânicas das pastas cruas e alvejadas dos bambus do Estado do Acre no que diz respeito a auto-ruptura e estouro se equivalem aos das pastas das folhosas. Entretanto, as resistências ao rasgo são semelhantes e algumas vezes superiores aos dos resinosos. Em relação as dobras -duplas os valores apresentados estão na mesma escala dos encontrados nas essências de fibra curta, sendo no entanto, inferior aos das madeiras de fibra longa.
Os papéis dos bambus são porosos e esponjosos e apresentam uma transparência nublosa; para certas fabricações são necessários visarem um refino de pasta com apareIhos que forneçam os cortes de fibras ou em misturas com pastas de fibras curtas. As pastas de bambus constituem então, um complemento propicio as pastas de folhosas ou de palhas.

Considerando os parâmetros de fabricação, observa-se que os papéis provenientes
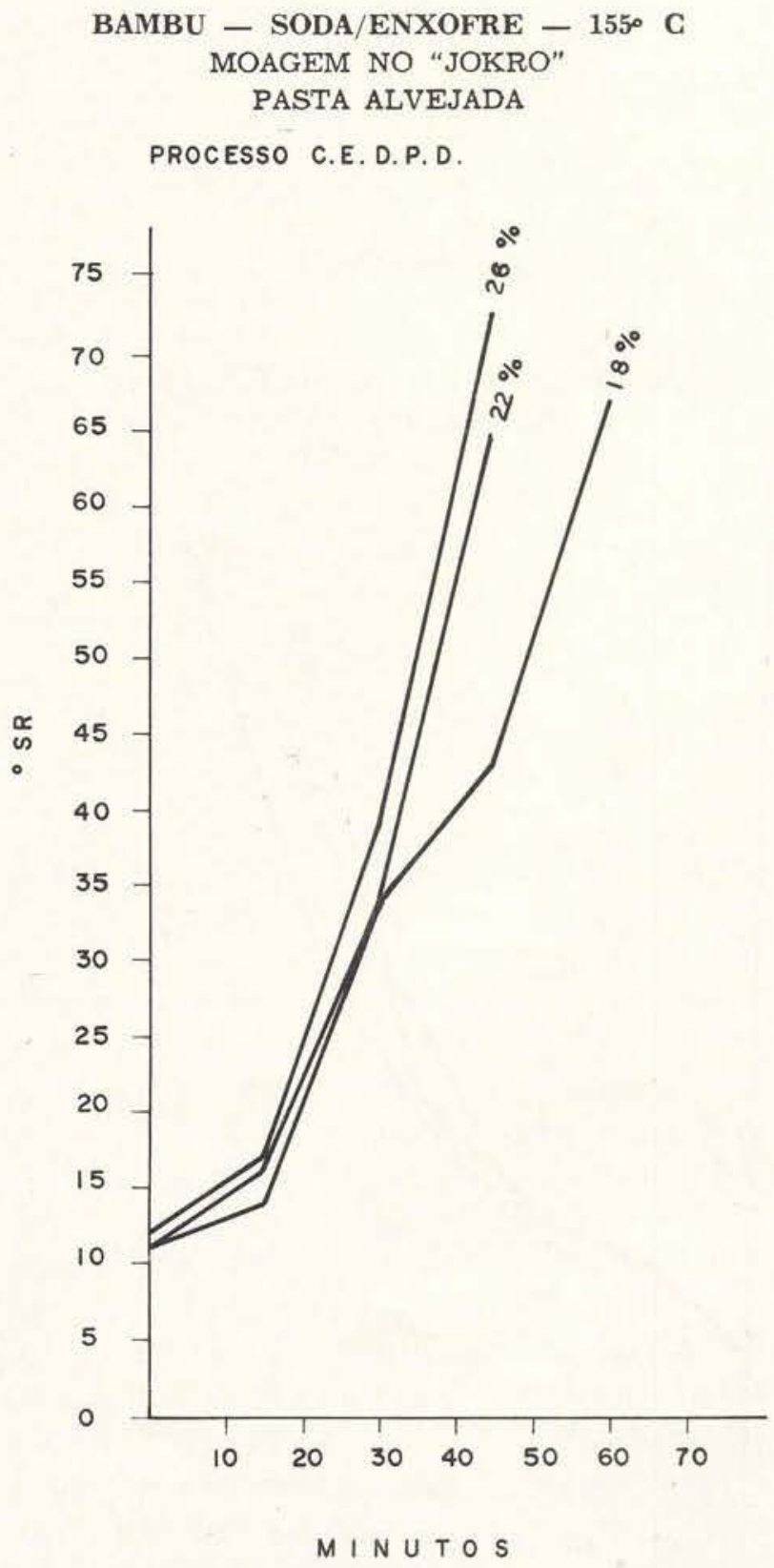

GRAFICO VII 


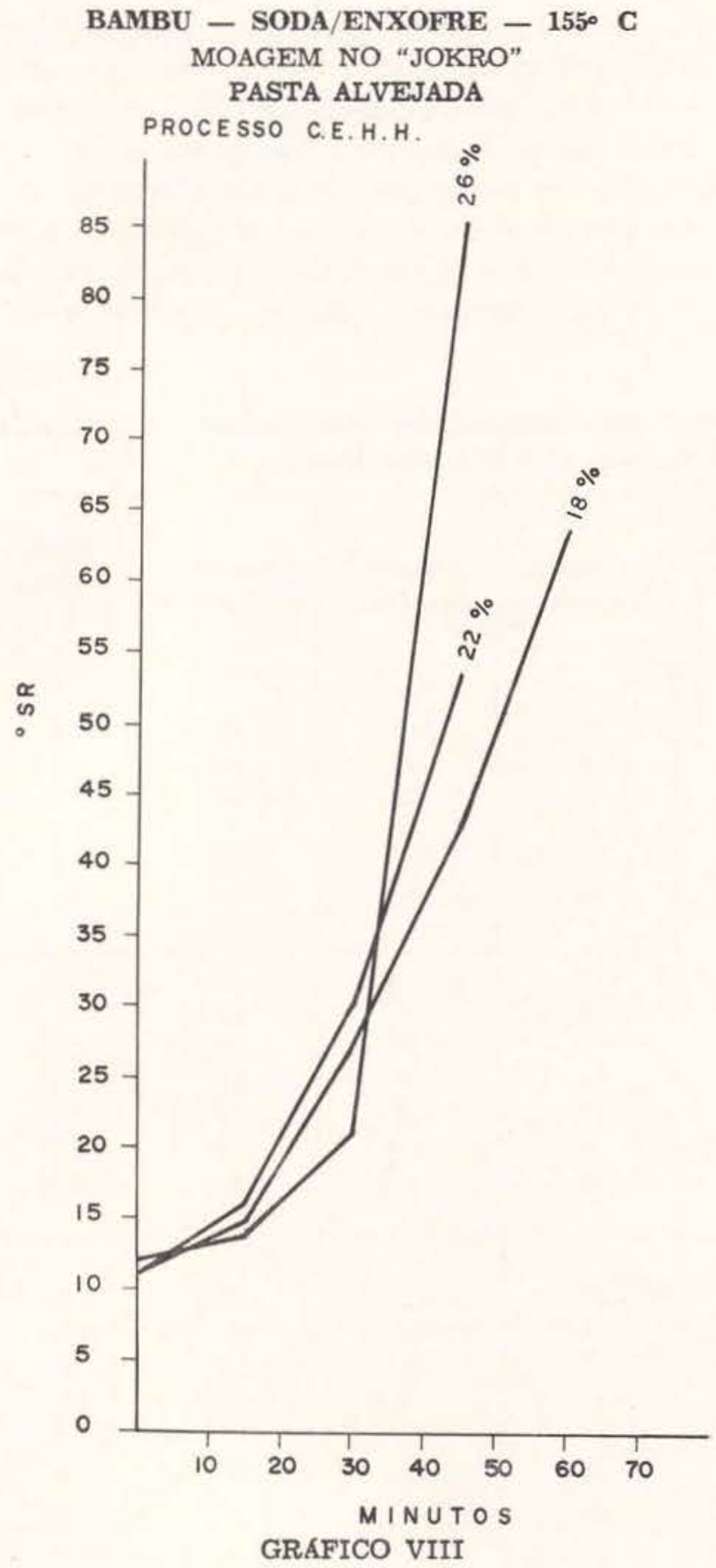

das cocções a $155^{\circ} \mathrm{C}$ com 3 horas de patamar, apresentaram as suas resistências moderadamente superiores aos verificados para os cozimentos a $170^{\circ} \mathrm{C}$, significando que se poderá rebaixar de alguns pontos a temperatura de cocção rápida sem afetar as características mecânicas dos papéis.

No que diz respeito aos percentuais de álcali, as resistências das pastas decresceram, da menor para a maior quantidade de $\mathrm{NaOH}$ introduzido, o que é normal, em razão das características do ataque com maior quantidade de $\mathrm{NaOH}$ causarem freqüentemente uma maior degradação da celulose.

Em que concerne os alvejamentos, as pastas alvejadas em cinco fases forneceram papéis que apresentaram uma nítida vantagem em comparação aos das pastas branqueadas com o hipoclorito, por serem os agentes químicos, bióxido de cloro e peróxidos, mais seletivos e atacarem a celulose com menor intensidade do que normalmente o observado no alvejamento C.E.H.H.

A análise das características mecânicas dos papéis refinados entre os equipamentos, evidencia que as pastas engrossadas nos moinhos "Bauer" e "Jokro" apresentaram resistências superiores aos das pastas refinadas no moinho "Holandesa" e, entre múltiplos fatores que influenciaram nesta ocorrência, devem ser levados em consideração a velocidade de refino e o ângulo de corte (Brecht, 1967).

Em relação aos processos de fabricação, as resistências das pastas cruas obtidas pelo processo à Soda são mais fracas do que as conseguidas pelo processo Soda/Enxofre. Esta diferença também foi observada para as pastas alvejadas (Ver Quadro n. III).

OBTENÇÃO DE PASTAS DE ALTO REDIMENTO DO BAMBU

As amostras do bambu do Estado do Acre foram tratadas pelos procedimentos Semiquimico e Mecano-químico, visando a obtenção de pastas de alto rendimento.

\section{Pasta semiquímica do bambu}

O processo utilizado para o ensaio de fabricação desta categoria de pasta foi o N.S.S.C. e as seguintes condições de tratamentos foram estabelecidas:

\begin{tabular}{c|c|c|c|c|c}
\hline $\begin{array}{c}\text { Coxt- } \\
\text { mente } \\
\mathrm{N} .0\end{array}$ & $\begin{array}{c}\mathrm{Na}_{2} \mathrm{SO}_{3} \\
\%\end{array}$ & $\begin{array}{c}\mathrm{Ne}_{2} \mathrm{CO}_{3} \\
\%\end{array}$ & $\begin{array}{c}\text { Patamar } \\
\text { interme- } \\
\text { diário }\end{array}$ & $\begin{array}{c}\text { Patamar } \\
\text { defini- } \\
\text { tivo }\end{array}$ & Dilulsc̆。 \\
\hline 307 & 24 & 8 & $1 \mathrm{~h}-110^{\circ} \mathrm{C}$ & $3 \mathrm{~h}-165^{\circ} \mathrm{C}$ & $4,5: 1$ \\
308 & 18 & 6 & & \\
\hline
\end{tabular}


Os resultados dos cozimentos N.S.S.C. são mostrados na Tabela $\mathrm{n} .^{\circ}$ XIII.

Os bambus estudados são facilmente tratados pelo procedimento ao sulfito neutro e apresentaram seu indice de deslignificação alto, com um $\mathrm{N}^{\circ}$ de $\mathrm{KMnO}_{4}$ com resultados muito baixos para este tipo de cocção.
Ao contrário do que se observa com as madeiras cujas pastas obtidas por este procedimento ainda se apresenta bastante lignificada, necessitando para sua utilização de um tratamento mecânico complementar. As pastas dos bambus do Acre mostraram-se bem deslignificadas e no conjunto suas características se relacionam mais como pastas quími-

TABELA N.0 IX - Características das pastas cruas dos cozimentos soda/enxofre do bambu do Estado do Acre, resultados interpolados a $45^{\circ} \mathrm{SR}$, moagem na Holandesa, no Jokro e no Bauer.

\begin{tabular}{|c|c|c|c|c|c|c|c|c|c|}
\hline $\begin{array}{l}\text { Equipa- } \\
\text { mento }\end{array}$ & $\begin{array}{c}\text { Cozi- } \\
\text { mento } \\
\text { N. }\end{array}$ & $\begin{array}{l}\text { Auto. } \\
\text { ruptura } \\
\text { m }\end{array}$ & $\begin{array}{c}\text { Rasgo } \mathrm{g} \\
\text { por } \\
100 \mathrm{~g} / \mathrm{m}^{2}\end{array}$ & $\begin{array}{r}\text { Estouro } \\
\mathrm{Kg} / \mathrm{cm}^{2} \\
100 \mathrm{~g} / \mathrm{m}^{2}\end{array}$ & $\begin{array}{c}\text { Dobras } \\
\text { duplas } \\
\text { N.॰ }\end{array}$ & $\begin{array}{c}\text { Porosidade } \\
\text { Seg/100c.c. }\end{array}$ & $\begin{array}{c}\text { Lisura } \\
\text { Seg/50c.c. }\end{array}$ & $\begin{array}{c}\text { Maciez } \\
\text { Seg/100c.c. }\end{array}$ & $\begin{array}{l}\text { Alonga- } \\
\text { mento } \\
\%\end{array}$ \\
\hline $\begin{array}{l}\text { Holan- } \\
\text { desa }\end{array}$ & $\begin{array}{l}300 \\
298 \\
296 \\
304 \\
303 \\
302\end{array}$ & $\begin{array}{l}4.098 \\
2.706 \\
2.550 \\
4.275 \\
4.022 \\
3.935\end{array}$ & $\begin{array}{l}48 \\
42 \\
36 \\
57 \\
57 \\
40\end{array}$ & $\begin{array}{l}0,6 \\
0,0 \\
0,0 \\
0,7 \\
0,9 \\
0,7\end{array}$ & $\begin{array}{l}4,0 \\
3,0 \\
2,0 \\
6,0 \\
5,0 \\
4,0\end{array}$ & $\begin{array}{r}33 \\
7 \\
10 \\
36 \\
63 \\
53\end{array}$ & $\begin{array}{l}18 \\
27 \\
27 \\
24 \\
26 \\
38\end{array}$ & $\begin{array}{l}24 \\
37 \\
36 \\
35 \\
35 \\
35\end{array}$ & $\begin{array}{l}1,4 \\
1,2 \\
1,2 \\
1,3 \\
1,6 \\
1,0\end{array}$ \\
\hline Jokro & $\begin{array}{l}300 \\
298 \\
296 \\
304 \\
303 \\
302\end{array}$ & $\begin{array}{l}5.297 \\
5.656 \\
5.553 \\
5.814 \\
5.091 \\
6.238\end{array}$ & $\begin{array}{l}162 \\
132 \\
115 \\
125 \\
161 \\
113\end{array}$ & $\begin{array}{l}4,0 \\
3,0 \\
2,0 \\
4,0 \\
3,5 \\
3,2\end{array}$ & $\begin{array}{l}74,0 \\
29,0 \\
18,0 \\
90,0 \\
96,0 \\
43,0\end{array}$ & $\begin{array}{r}9 \\
9 \\
6 \\
9 \\
52 \\
15\end{array}$ & $\begin{array}{l}23 \\
26 \\
30 \\
30 \\
23 \\
30\end{array}$ & $\begin{array}{l}33 \\
37 \\
34 \\
36 \\
37 \\
33\end{array}$ & $\begin{array}{l}2,5 \\
2,1 \\
2,0 \\
2,3 \\
2,7 \\
2,0\end{array}$ \\
\hline Bauer & $\begin{array}{l}300 \\
298 \\
296 \\
304 \\
303 \\
302\end{array}$ & $\begin{array}{l}5.613 \\
4.952 \\
5.196 \\
6.732 \\
5.382 \\
5.728\end{array}$ & $\begin{array}{l}160 \\
149 \\
118 \\
158 \\
154 \\
140\end{array}$ & $\begin{array}{l}3,1 \\
2,4 \\
2,5 \\
3,0 \\
3,0 \\
3,0\end{array}$ & $\begin{array}{r}216,0 \\
55,0 \\
40,0 \\
147,0 \\
143,0 \\
40,0\end{array}$ & $\begin{array}{l}16 \\
25 \\
21 \\
19 \\
54 \\
13\end{array}$ & $\begin{array}{l}20 \\
20 \\
24 \\
18 \\
23 \\
13\end{array}$ & $\begin{array}{l}43 \\
43 \\
37 \\
40 \\
43 \\
38\end{array}$ & $\begin{array}{l}2,0 \\
1,5 \\
1,2 \\
1,5 \\
2,0 \\
1,4\end{array}$ \\
\hline
\end{tabular}

TABELA N. X - Características das pastas cruas dos cozimentos à soda do bambu do Estado do Acre, resultados interpolados a $45^{\circ} \mathrm{SR}$ - moagem no Bauer.

\begin{tabular}{|c|c|c|c|c|c|c|c|c|c|}
\hline $\begin{array}{l}\text { Equipa- } \\
\text { mento }\end{array}$ & $\begin{array}{l}\text { Cozi- } \\
\text { mento } \\
\text { N. }\end{array}$ & $\begin{array}{l}\text { Auto- } \\
\text { ruptura } \\
\text { m }\end{array}$ & $\begin{array}{c}\text { Rasgo } \mathrm{g} \\
\text { por } \\
100 \mathrm{~g} / \mathrm{m}^{2}\end{array}$ & $\begin{array}{l}\text { Estouro } \\
\mathrm{Kg} / \mathrm{cm}^{2} \\
100 \mathrm{~g} / \mathrm{m}^{2}\end{array}$ & $\begin{array}{c}\text { Dobras- } \\
\text { Duplas } \\
\text { N. }\end{array}$ & $\begin{array}{l}\text { Porosidade } \\
\text { Seg/100c.c. }\end{array}$ & $\begin{array}{c}\text { Lisura } \\
\text { Seg/50c.c. }\end{array}$ & $\begin{array}{c}\text { Maciez } \\
\text { Seg/100c.c. }\end{array}$ & $\begin{array}{c}\text { Alonga- } \\
\text { mento } \\
\%\end{array}$ \\
\hline \multirow{2}{*}{ Bauer } & 305 & 4.308 & 141 & 2,0 & 41,0 & 9 & 14 & 47 & 1,0 \\
\hline & 306 & 4.645 & 145 & 1,4 & 43,0 & 5 & 13 & 39 & 1,0 \\
\hline
\end{tabular}


cas do que pastas semiquímicas. As pastas são claras e em relação ao rendimento e dureza são semelhantes aos das pastas quimicas Soda/Enxofre. As quantidades de $\mathrm{SO}_{2}$ livre e combinado nas lixívias residuais não chegam a serem relevantes, que tornem as condições retidas proibitivas para o tratamento em termos de realização industrial.
Clareamento das Pastas Semiquímicas do bambu

As pestas cruas obtidas dos cozimentos ao sulfito neutro foram submetidas a $\iota \mathrm{m}$ processo de clareamento com $\mathrm{H}_{2} \mathrm{O}_{2}$ (peróxido de hidrogênio) usualmente aplicado para as pastas de alto rendimento com percentuais as-

QUADRO N. III - Quadro comparativo das características de resistências das pastas cruas e alvejadas dos processos soda/enxofre $e^{*}$ à soda refinadas em moinho Bauer.

\section{PASTAS CRUAS}

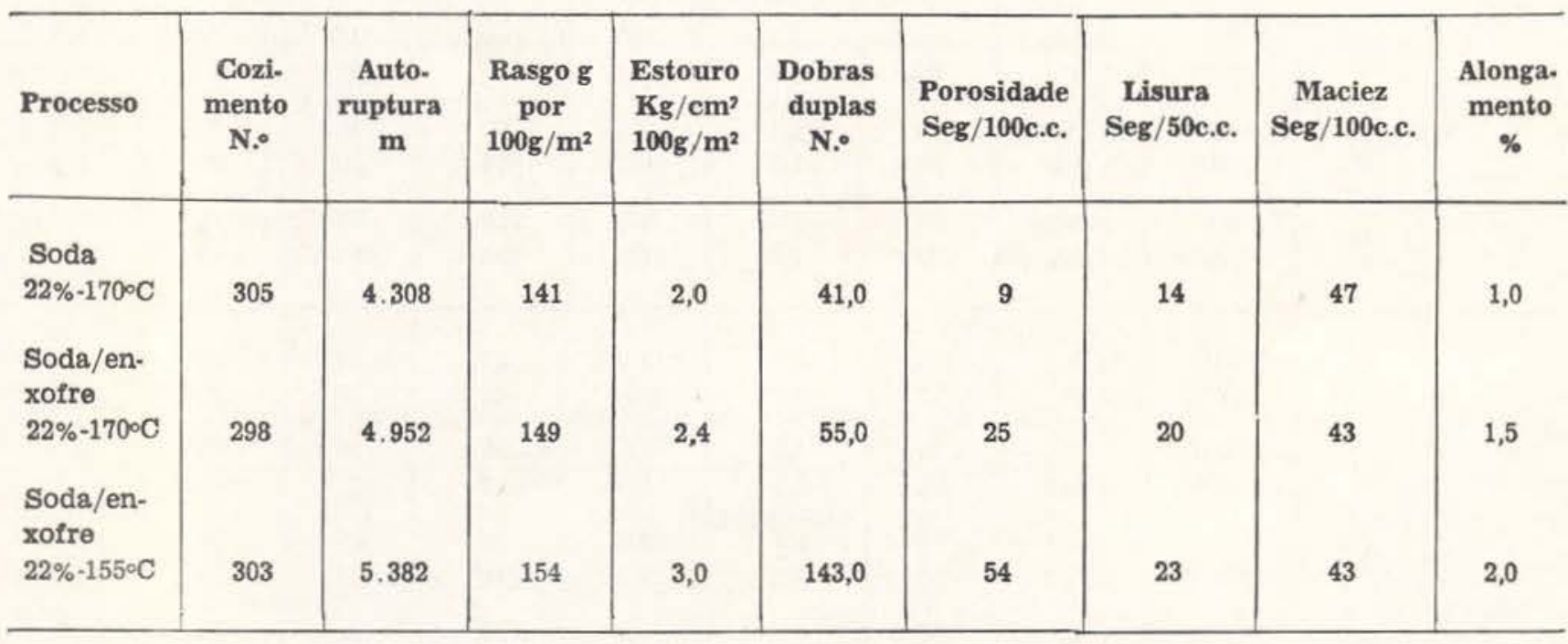

PASTAS ALVEJADAS

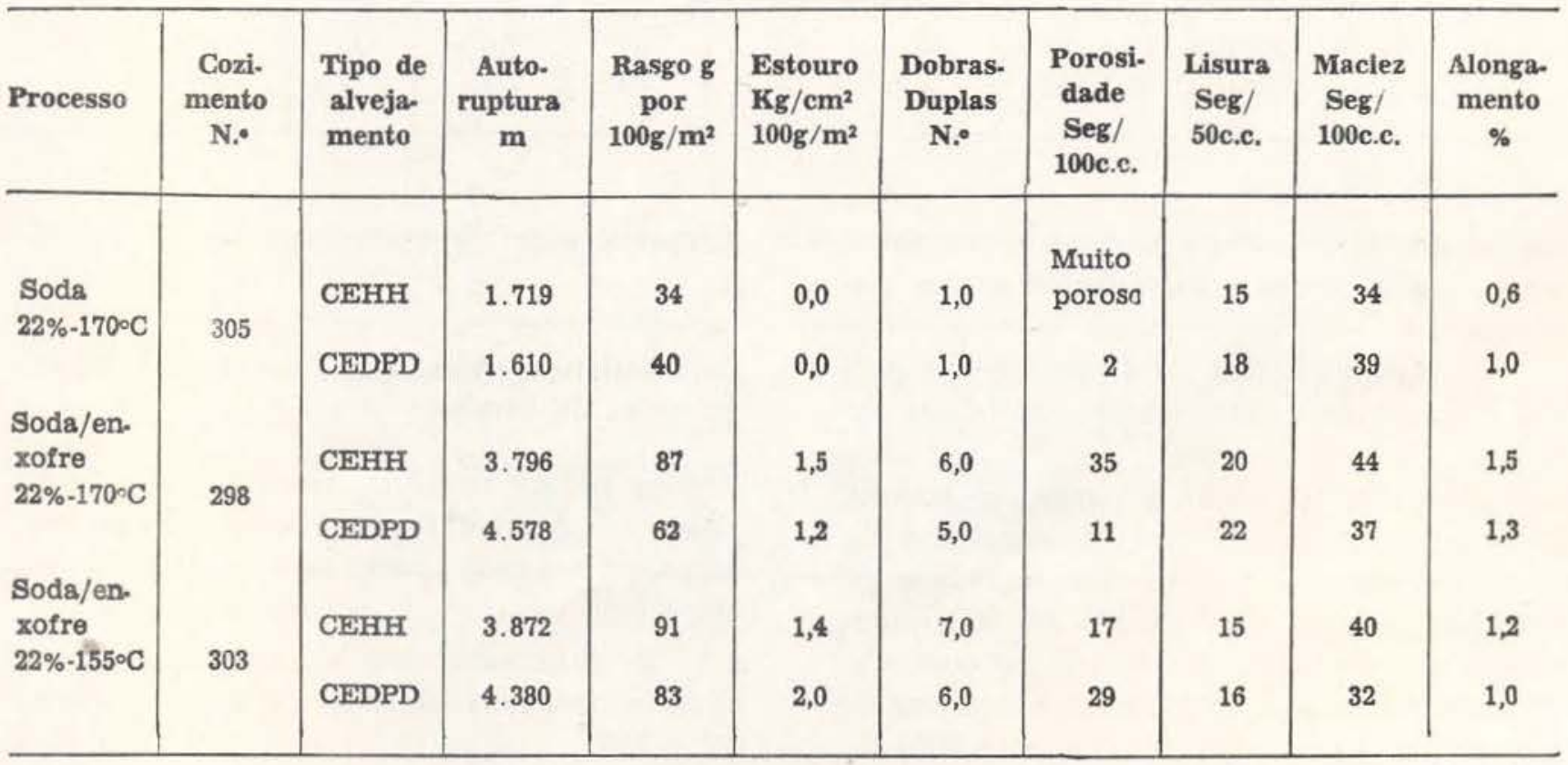


TABELA N. XI - Características das pastas alvejadas dos cozimentos soda/enxofre do bambu do Estado do Acre, resultados interpolados a $45 \circ \mathrm{SR}$ - Moagem no Jokxo e Bauer.

\begin{tabular}{|c|c|c|c|c|c|c|c|c|c|c|}
\hline $\begin{array}{l}\text { Equipa- } \\
\text { mento }\end{array}$ & $\begin{array}{l}\text { Cozi- } \\
\text { mento } \\
\text { N. }\end{array}$ & $\begin{array}{l}\text { Processo } \\
\text { de alve- } \\
\text { jamento }\end{array}$ & $\begin{array}{l}\text { Auto- } \\
\text { ruptura } \\
\text { m }\end{array}$ & $\begin{array}{c}\text { Rasgo } \mathrm{g} \\
\text { por } \\
100 \mathrm{~g} / \mathrm{m}^{2}\end{array}$ & $\begin{array}{r}\text { Estouro } \\
\mathrm{Kg} / \mathrm{cm}^{2} \\
100 \mathrm{~g} / \mathrm{m}^{2}\end{array}$ & $\begin{array}{c}\text { Dobras- } \\
\text { duplas } \\
\text { N.० }\end{array}$ & $\begin{array}{l}\text { Porosi- } \\
\text { dade } \\
\text { Seg/ } \\
100 \text { c.c. }\end{array}$ & $\begin{array}{c}\text { Lisura } \\
\text { Seg/ } \\
\text { 50c.c. }\end{array}$ & $\begin{array}{c}\text { Maciez } \\
\text { Seg/ } \\
100 \text { c.c. }\end{array}$ & $\begin{array}{c}\text { Alonga- } \\
\text { mento } \\
\%\end{array}$ \\
\hline \multirow{12}{*}{ Jokro } & \multirow{2}{*}{300} & $\mathrm{CEHH}$ & 4.807 & 102 & 2,5 & 13,0 & 4 & 19 & 33 & 2,0 \\
\hline & & CEDPD & 6.129 & 122 & 3,2 & 35,0 & 7 & 22 & 35 & 2,0 \\
\hline & \multirow{2}{*}{298} & CEHH & 3.830 & 69 & 1,0 & 4,0 & 8 & 26 & 33 & 1,5 \\
\hline & & CEDPD & 3.613 & 51 & 0,7 & 3,0 & 28 & 25 & 33 & 1,6 \\
\hline & \multirow{2}{*}{296} & $\mathrm{CEHH}$ & 2.840 & 39 & 0,0 & 2,0 & 6 & 28 & 36 & 0,6 \\
\hline & & CEDPD & 2,313 & 35 & 0,0 & 2,0 & 4 & 35 & 36 & 0,6 \\
\hline & \multirow{2}{*}{304} & CEHH & 5.168 & 80 & 2,0 & 9,0 & 9 & 24 & 34 & 2,0 \\
\hline & & CEDPD & 5.928 & 86 & 3,0 & 18,0 & 15 & 28 & 35 & 2,0 \\
\hline & \multirow{2}{*}{303} & $\mathrm{CEHH}$ & 3.498 & 57 & 1,0 & 3,0 & 10 & 25 & 35 & 1,2 \\
\hline & & CEDPD & 4.278 & 55 & 1,3 & 5,0 & 72 & 33 & 33 & 2,0 \\
\hline & \multirow{2}{*}{302} & CEHH & 3.960 & 99 & 1,3 & 6,0 & 219 & 39 & 31 & 2,0 \\
\hline & & CEDPD & 3.922 & 53 & 1,0 & 3,0 & 32 & 37 & 32 & 1,0 \\
\hline \multirow{12}{*}{ Bauer } & \multirow{2}{*}{300} & CEHH & 5.392 & 102 & 2,0 & 15,0 & 22 & 20 & 35 & 1,3 \\
\hline & & CEDPD & 5.562 & 126 & 3,0 & 42,0 & 44 & 16 & 33 & 1,5 \\
\hline & \multirow{2}{*}{298} & $\mathrm{CEHH}$ & 3.796 & 87 & 1,5 & 6,0 & 35 & 20 & 44 & 1,5 \\
\hline & & CEDPD & 4.578 & 62 & 1,2 & 5,0 & 11 & 22 & 37 & 1,3 \\
\hline & \multirow{2}{*}{296} & CEHH & 4.604 & 70 & 1,3 & 3,0 & 6 & 25 & 36 & 1,0 \\
\hline & & CEDPD & 4. 352 & 97 & 1,1 & 3,0 & 48 & 22 & 34 & 1,3 \\
\hline & \multirow{2}{*}{304} & $\mathrm{CEHH}$ & 4.454 & 93 & 1,5 & 11,0 & 16 & 18 & 34 & 1,2 \\
\hline & & CEDPD & 5.055 & 96 & 2,3 & 21,0 & 18 & 18 & 34 & 1,4 \\
\hline & \multirow{2}{*}{303} & CEHH & 3.872 & 91 & 1,4 & 7,0 & 17 & 15 & 40 & 1,2 \\
\hline & & CEDPD & 4.380 & 83 & 2,0 & 6,0 & 29 & 16 & 32 & 1,0 \\
\hline & \multirow{2}{*}{302} & $\mathrm{CEHH}$ & 4.832 & 90 & 2,0 & 4,6 & 10 & 18 & 37 & 1,2 \\
\hline & & CEDPD & 5.452 & 75 & 2,0 & 8,0 & 29 & 20 & 39 & 1,3 \\
\hline
\end{tabular}

cendentes, a fim de se analisar o comportamento evolutivo das alvuras frente a este clareante.

Os resultados dos clareamentos das pastas Semiquímicas são vistos na Tabela N. XIV.

Como era esperado, a pasta proveniente do cozimento com maior percentagem de reagente ofereceu uma maior facilidade de clareamento e ao nível de $5 \%$ de $\mathrm{H}_{2} \mathrm{O}_{2}$ apresentou um Photovolt satisfatório ao contrário da pasta obtida com $18 \% \quad \mathrm{Na}_{2} \mathrm{SO}_{3}$ e $6 \% \quad \mathrm{Na}_{2} \mathrm{CO}_{3}$ cuja alvura apresentada no nível mais alto de clareante pode ser considerada como mediocre.

\section{Características Mecânicas das Pastas Semi- químicas do bambu}

As pastas cruas e clareadas foram refinadas em moinho "Bauer", com a mesma metodologia aplicada para as pastas químicas, até atingir um grau de engorda desejado.

Os resultados dos ensaios das pastas cruas e clareadas são vistos nas Tabelas $\mathrm{N}^{\circ} \mathrm{s}$. $X V$ e XVI. 
As resistências mecânicas das pastas cruas e clareadas são razoáveis, mas inferiores às apresentadas pelas pastas químicas.

Entre os tratamentos, observa-se que as resistências dos papéis obtidos das pastas fa- bricadas com menor percentagem de reagentes foram melhores, tendo como único inconveniente de apresentar uma porosidade um tanto elevada, mas que năo chega a ser um problema significativo na utilização dos papéis.

TABELA N. XII - Características das pastas alvejadas dos cozimentos à soda do bambu do Estado do Acre, resultados interpolados a $45 \cdot \mathrm{SR}$ - Moagem do Bauer.

\begin{tabular}{|c|c|c|c|c|c|c|c|c|c|c|}
\hline $\begin{array}{c}\text { Equipa- } \\
\text { mento }\end{array}$ & $\begin{array}{l}\text { Cozi- } \\
\text { mento }\end{array}$ & $\begin{array}{l}\text { Processo } \\
\text { de alve- } \\
\text { jamento }\end{array}$ & $\begin{array}{c}\text { Auto- } \\
\text { ruptura } \\
\text { m }\end{array}$ & $\begin{array}{c}\text { Rasgo } \mathrm{g} \\
\text { por } \\
100 \mathrm{~g} / \mathrm{m}^{2}\end{array}$ & $\begin{array}{l}\text { Estouro } \\
\mathrm{Kg} / \mathrm{cm}^{2} \\
100 \mathrm{~g} / \mathrm{m}^{2}\end{array}$ & $\begin{array}{c}\text { Dobras- } \\
\text { duplas } \\
\text { N.॰ }\end{array}$ & $\begin{array}{c}\text { Porosi- } \\
\text { dade } \\
\text { Seg/ } \\
\text { 100c.c. }\end{array}$ & $\begin{array}{l}\text { Lisura } \\
\text { Seg/ } \\
\text { 50c.c. }\end{array}$ & $\begin{array}{c}\text { Maciez } \\
\text { Seg/ } \\
100 c . c .\end{array}$ & $\begin{array}{c}\text { Alonga- } \\
\text { mento } \\
\%\end{array}$ \\
\hline \multirow{4}{*}{ Bauer } & \multirow[t]{2}{*}{305} & СЕHН & 1.719 & 34 & 0,0 & 1,0 & $\begin{array}{l}\text { Muito } \\
\text { poroso }\end{array}$ & 15 & 34 & 0,6 \\
\hline & & CEDPD & 1.610 & 40 & 0,0 & 1,0 & 1,4 & 18 & 39 & 1,0 \\
\hline & \multirow{2}{*}{306} & CEHH & 2.754 & 75 & 0,0 & 2,0 & 4,0 & 21 & 38 & 1,2 \\
\hline & & CEDPD & 5.422 & 162 & 2,5 & 132,0 & 6,0 & 19 & 33 & 2,0 \\
\hline
\end{tabular}

TABELA N. XII - Resultados dos cozimentos monosulfite $\left(\mathrm{SO}_{3} \mathrm{Na}_{2} \cdot \mathrm{CO}_{3} \mathrm{Na}_{2}\right)$ do bambu do Estado do Acre

\begin{tabular}{|c|c|c|c|c|c|c|c|c|c|}
\hline \multirow{2}{*}{$\begin{array}{l}\text { N.• dos co- } \\
\text { zimentos }\end{array}$} & \multirow{2}{*}{ Patamar } & \multirow{2}{*}{$\begin{array}{c}\mathrm{SO}_{3} \mathrm{Na}_{2} \\
\%\end{array}$} & \multirow{2}{*}{$\begin{array}{c}\mathrm{CO}_{3} \mathrm{Na}_{2} \\
\%\end{array}$} & \multicolumn{2}{|c|}{ Rendimento } & \multicolumn{2}{|c|}{$\mathrm{SO}_{2}$} & \multirow{2}{*}{$\begin{array}{c}\text { "Photovolt" } \\
\text { alvura da } \\
\text { pasta }\end{array}$} & \multirow{2}{*}{$\begin{array}{l}\text { Indice de } \\
\text { KMn04 } \\
\text { (40 cc) }\end{array}$} \\
\hline & & & & $\begin{array}{c}\text { Bruto } \\
\%\end{array}$ & $\begin{array}{l}\text { Depu- } \\
\text { rado } \\
\%\end{array}$ & $\begin{array}{c}\text { Livre } \\
\text { g }\end{array}$ & $\begin{array}{c}\text { Combi- } \\
\text { nado } \\
\mathbf{g}\end{array}$ & & \\
\hline 307 & $3 \mathrm{~h}-165^{\circ} \mathrm{C}$ & 24 & 8 & 44 & 43 & 0,035 & 0,028 & 55 & 19 \\
\hline 308 & & 18 & 6 & 42 & 41 & 0,029 & 0,011 & 49 & 24 \\
\hline
\end{tabular}

TABELA N.- XIV - Resultados dos clareamentos $\left(\mathrm{H}_{2} \mathrm{O}_{2}\right)$ das pastas cruas dos cozimentos monosulfite do bambu do Estado do Acre.

\begin{tabular}{c|c|c|c|c|c|c|c|c|c}
\hline \multirow{2}{*}{$\begin{array}{c}\text { Nos. dos } \\
\text { cozimentos }\end{array}$} & \multicolumn{4}{|c|}{1. Ensaio: $\mathrm{H}_{2} \mathrm{O}_{2}$} & \multicolumn{3}{c|}{ 2. Ensaio: $\mathrm{F}_{2} \mathrm{O}_{2}$} & \multicolumn{3}{c}{3. Ensaio: $\mathrm{H}_{2} \mathrm{O}_{2}$} \\
\cline { 2 - 9 } & $\begin{array}{c}\mathrm{H}_{2} \mathrm{O}_{2} \\
\text { int. } \\
\%\end{array}$ & $\begin{array}{c}\mathrm{H}_{2} \mathrm{O}_{2} \\
\text { cons. } \\
\%\end{array}$ & $\begin{array}{c}\text { "Photovolt" } \\
\text { Alvura da } \\
\text { pasta }\end{array}$ & $\begin{array}{c}\mathrm{H}_{2} \mathrm{O}_{2} \\
\text { int. } \\
\%\end{array}$ & $\begin{array}{c}\mathrm{H}_{2} \mathrm{O}_{2} \\
\text { cons. } \\
\%\end{array}$ & $\begin{array}{c}\text { "Photovolt" } \\
\text { Alvura da } \\
\text { pasta }\end{array}$ & $\begin{array}{c}\mathrm{H}_{2} \mathrm{O}_{2} \\
\text { int. } \\
\%\end{array}$ & $\begin{array}{c}\mathrm{H}_{2} \mathrm{O}_{2} \\
\text { cons. } \\
\%\end{array}$ & $\begin{array}{c}\text { "Photovolt" } \\
\text { Alvura da } \\
\text { pasta }\end{array}$ \\
\hline 307 & 2,0 & 2,0 & 57 & 5,0 & 5,0 & 62 & 10,0 & 10,0 & 68 \\
308 & 2,0 & 2,0 & 49 & 5,0 & 5,0 & 53 & 10,0 & 10,0 & 57 \\
\hline
\end{tabular}


TABELA N. XV - Características das pastas cruas dos cozimentos monosulfite do bambu do Estado do Acre, resultados interpolados a $45 \circ \mathrm{SR}$ - Moagem no Bauer.

\begin{tabular}{|c|c|c|c|c|c|c|c|c|c|}
\hline $\begin{array}{l}\text { Equipa- } \\
\text { mento }\end{array}$ & $\begin{array}{l}\text { Nos, dos } \\
\text { cozi- } \\
\text { mentos }\end{array}$ & $\begin{array}{c}\text { Auto. } \\
\text { ruptura } \\
\text { m }\end{array}$ & $\begin{array}{c}\text { Rasgo } \mathrm{g} \\
\text { por } \\
100 \mathrm{~g} / \mathrm{m}^{2}\end{array}$ & $\begin{array}{l}\text { Estouro } \\
\mathrm{Kg} / \mathrm{cm}^{2} \\
100 \mathrm{~g} / \mathrm{m}^{2}\end{array}$ & $\begin{array}{c}\text { Dobras } \\
\text { duplas } \\
\text { N.॰ }\end{array}$ & $\begin{array}{l}\text { Porosidade } \\
\text { Seg/100c.c. }\end{array}$ & $\begin{array}{c}\text { Lisura } \\
\text { Seg/50c.c. }\end{array}$ & $\begin{array}{c}\text { Maciez } \\
\text { Seg/100c.c. }\end{array}$ & $\begin{array}{c}\text { Alonga- } \\
\text { mento } \\
\%\end{array}$ \\
\hline \multirow{2}{*}{ Bauer } & 307 & 5.011 & 127 & 1,6 & 72,0 & 18 & 9 & 30 & 1,0 \\
\hline & 308 & 4. 602 & 132 & 1,6 & 23,0 & 8 & 14 & 34 & 1,0 \\
\hline
\end{tabular}

TABELA N. XVI - Características das pastas clareadas $\left(\mathrm{H}_{2} \mathrm{O}_{2}\right)$ dos cozimentos monosulfite do bambu do Estado do Acre, resultados interpolados a $45 \circ \mathrm{SR}$ - Moagem no Bauer.

\begin{tabular}{|c|c|c|c|c|c|c|c|c|c|c|}
\hline $\begin{array}{l}\text { Equipa- } \\
\text { mento }\end{array}$ & $\begin{array}{l}\text { Nos. dos } \\
\text { cozi. } \\
\text { mentos }\end{array}$ & $\begin{array}{l}\text { Processo } \\
\text { de cla- } \\
\text { reamento }\end{array}$ & $\begin{array}{l}\text { Auto- } \\
\text { ruptura } \\
\text { m }\end{array}$ & $\begin{array}{c}\text { Rasgo } \mathrm{g} \\
\text { por } \\
100 \mathrm{~g} / \mathrm{m}^{2}\end{array}$ & $\begin{array}{r}\text { Estouro } \\
\mathrm{Kg} / \mathrm{cm}^{2} \\
100 \mathrm{~g} / \mathrm{m}^{2}\end{array}$ & $\begin{array}{c}\text { Dobras- } \\
\text { duplas } \\
\text { N.。 }\end{array}$ & $\begin{array}{c}\text { Porosida- } \\
\text { de Seg/ } \\
\text { 100c.c. }\end{array}$ & $\begin{array}{c}\text { Lisura } \\
\text { Seg/ } \\
\text { 50c.c. }\end{array}$ & $\begin{array}{c}\text { Maciez } \\
\text { Seg/ } \\
\text { 100c.c. }\end{array}$ & $\begin{array}{c}\text { Alonga- } \\
\text { mento } \\
\%\end{array}$ \\
\hline Bauer & $\begin{array}{l}307 \\
308\end{array}$ & $\mathrm{H}_{2} \mathrm{O}_{2}$ & $\begin{array}{l}4.404 \\
4.852\end{array}$ & 109 & 2,0 & 21,0 & 14 & 12 & 30 & 1,7 \\
\hline
\end{tabular}

Pastas Alcalinas Mecano-Químico do bambu

Procedeu-se com as amostras do bambu do Estado do Acre ensaios de fabricação de pasta de alto rendimento por cocções alcalinas a baixa temperatura, seguido de uma passagem em desfibrador.

Três séries de cozimentos foram efetuados pelo método Soda/Enxofre. As quantidades de álcalis introduzidos variaram de $18 \%$ à $26 \%$. Os estudos foram realizados com três diferentes temperaturas: à $100^{\circ} \mathrm{C}, 125^{\circ} \mathrm{C}$ e $135^{\circ} \mathrm{C}$, com o tempo na temperatura de patamar variando de 3 a 9 horas, em um cozinhador rotativo de 10 litros, aquecimento elétrico e $1 \mathrm{rpm}$.

Logo após ao término dos cozimentos foram retiradas uma pequena quantidade de Iixívia para a determinação de $\mathrm{NaOH}$ residual. Em seguida os cavacos ainda impregnados foram lavados e encaminhados para o desfibrador Sprout Waldron Mod. D2-202, potência de desfibragem de 40 C.V., disco n. 17.804 , com afastamento dos discos na ordem de cinco unidades de polegadas, para a obtenção de pastas. Os demais procedimentos foram idênticos aos efetuados para as pastas químicas para a determinação dos rendimentos brutos e depurados, rejeitos sobre a madeira seca, alvura das pastas e índices de $\mathrm{KMnO}_{4}$. Os resultados dos cozimentos Mecano-Químico do bambu estão indicados na Tabela $\mathrm{N} \cdot \mathrm{XVII}$.

Os resultados obtidos mostraram que é possível se obter dos bambus do Acre pastas Mecano-Químico por cocções alcalinas a baixa temperatura.

Analisando os parâmetros retidos em relação aos resultados apresentados, as seguintes considerações poderão ser feitas:

- No que diz respeito a percentagem de reagente introduzido, aquele que evidenciou ser mais aconselhável para obtenção desta categoria de pasta foi o cozimento efetuado a um nível de $18 \%$ de $\mathrm{NaOH}$, por fornecer pastas com características nitidamente mecano-químico (alto rendimento e baixo grau de deslignificação). Os ensaios efetuados nos de- 
TABELA N.॰ XVII - Resultados dos cozimentos mecano-quimico do bambu do Estado do Acre.

\begin{tabular}{|c|c|c|c|c|c|c|c|c|}
\hline \multirow{2}{*}{$\begin{array}{c}\text { Cozimento } \\
\text { N. }\end{array}$} & \multirow{2}{*}{ Patamar } & \multirow{2}{*}{$\underset{\%}{\mathrm{NaOH}}$} & \multirow{2}{*}{$\begin{array}{l}\text { S } \\
\%\end{array}$} & \multirow{2}{*}{$\begin{array}{c}\text { Indice } \\
\text { de } \\
\text { KMn0, }\end{array}$} & \multicolumn{2}{|c|}{ RENDIMENTO } & \multirow{2}{*}{$\begin{array}{c}\mathrm{NaOH} \\
\mathrm{g} / \mathbf{1}\end{array}$} & \multirow{2}{*}{$\begin{array}{c}\text { "Photovolt" } \\
\text { alvura da } \\
\text { pasta }\end{array}$} \\
\hline & & & & & $\begin{array}{c}\text { Bruto } \\
\%\end{array}$ & $\begin{array}{c}\text { Depurado } \\
\%\end{array}$ & & \\
\hline 317 & $3 \mathrm{~h}-135^{\circ} \mathrm{C}$ & 26 & 2,6 & 26 & 40 & 40 & 18,0 & 52 \\
\hline 318 & $5 \mathrm{~h}-125^{\circ} \mathrm{C}$ & 26 & 2,6 & 28 & 42 & 48 & 17,0 & 53 \\
\hline 319 & $9 \mathrm{~h}-100^{\circ} \mathrm{C}$ & 26 & 2,6 & 29 & 48 & 48 & 14,0 & 49 \\
\hline 320 & $3 \mathrm{~h}-100^{\circ} \mathrm{C}$ & 22 & 2,2 & 30 & 50 & 50 & 10,0 & 50 \\
\hline 321 & $3 \mathrm{~h}-100^{\circ} \mathrm{C}$ & 18 & 1,8 & 39 & 59 & 59 & 6,0 & 49 \\
\hline
\end{tabular}

mais niveis de $\mathrm{NaOH}$ apresentaram pastas de característica química com durezas elevadas;

- A temperatura mais adequada para o tratamento se situou ao nível de $100^{\circ} \mathrm{C}$ em razão de propiciar maiores acréscimos nos rendimentos e dá a celulose fabricada propriedades inerentes as pastas de alto rendimento;

- Pelos resultados apresentados nos diferentes tratamentos, pode-se concluir como aconselhável para a fabricação de pastas mecano-químico dos bambus as condiçōes de tratamento retidas para o cozimento de $n .^{\circ} 321$, o que em termos de realização industrial é uma vantagem, não somente pela rapidez do ciclo de cocção, como também por um menor dispêndio de calor;

- As pastas mecano-químico do bambu obtidas são susceptíveis de serem alvejadas por processo clássico (C.E.H.H.) ou em cinco fases (C.E.D.P.D.), porém a quantidade de cloro seria muito importante, o que torna proibitivo os seus empregos. Um simples clareamento com o hipoclorito poderia ser sugerido, porém o dispêndio de reativos seria ainda muito elevado.

E importante observar a possibilidade da cocção do bambu a $100^{\circ} \mathrm{C}$ e pressão atmosférica que é tecnologicamente vantajosa, uma vez quue existem poucas matérias-primas fibrosas capazes de fornecerem, com condiçōes bastantes simples pastas com qualidades sa- tisfatórias. Esta possibilidade de cocção sem pressão, representa uma vantagem para as regiões como a Amazônia, onde se poderia implantar pequenas unidades integradas de pasta e papel, utilizando este procedimento de fabricação para a obtenção de papéis de embalagens.

\section{Caracteristicas das Pastas Cruas do Tratamento Mecano-Químico}

As pastas cruas obtidas pelo procedimento Mecano-Químico foram refinadas em moinho "Bauer" a um grau de engorda superior a $45^{\circ} \mathrm{SR}$.

Para a efetivação dos ensaios físico-mecânicos, procedeu-se de maneira análoga aos executados para as pastas químicas e semiquímicas. Os resultados estăo consignados na tabela $n .^{\circ}$ XVIII.

Como se pode observar, as pastas cruas da amostra dos bambus do Acre, fabricadas pelo procedimento Mecano-Químico forneceram papéis, cujas resistências variaram de uma maneira geral em sentido inverso aos rendimentos, com exceção do fator rasgo que teve suas resistências variando no mesmo sentido, com valores crescentes acima de 100 , credenciando esta matéria-prima poder ser utilizada na fabricação de papéis de embalagem, que exijam alta resistência nesta característica. 
TABELA N. XVIII - Características das pastas cruas dos cozimentos mecano-químico do bambu do Estado do Acre. Resultados interpolados a $45 \circ \mathrm{SR}$ - Moagem do Bauer.

\begin{tabular}{l|c|c|c|c|c|c|c|c|c}
\hline $\begin{array}{l}\text { Equipa. } \\
\text { mento }\end{array}$ & $\begin{array}{c}\text { Nos. dos } \\
\text { cozi. } \\
\text { mentos }\end{array}$ & $\begin{array}{c}\text { Auto- } \\
\text { ruptura } \\
\mathbf{m}\end{array}$ & $\begin{array}{c}\text { Rasgo g } \\
\mathbf{p o r} \\
\mathbf{1 0 0 g} / \mathbf{m}^{2}\end{array}$ & $\begin{array}{c}\text { Estouro } \\
\mathbf{K g} / \mathbf{c m}^{\mathbf{2}} \\
\mathbf{1 0 0 g} / \mathbf{m}^{2}\end{array}$ & $\begin{array}{c}\text { Dobras- } \\
\text { duplas } \\
\mathbf{N} .0\end{array}$ & $\begin{array}{c}\text { Porosidade } \\
\text { Seg/100c.c. }\end{array}$ & $\begin{array}{c}\text { Lisura } \\
\text { Seg/50c.c. }\end{array}$ & $\begin{array}{c}\text { Maciez } \\
\text { Seg/100c.c. }\end{array}$ & $\begin{array}{l}\text { Alonga- } \\
\text { mento } \\
\%\end{array}$ \\
\hline \multirow{2}{*}{ Bauer } & 317 & 5.802 & 117 & 2,1 & 69,0 & 22 & 16 & 35 & 1,2 \\
& 318 & 5.458 & 122 & 3,0 & 65,0 & 87 & 14 & 34 & 1,7 \\
& 319 & 5.530 & 142 & 2,0 & 75,0 & 66 & 16 & 33 & 1,3 \\
& 320 & 5.265 & 160 & 2,4 & 73,0 & 8 & 14 & 41 & 1,6 \\
& 321 & 4.960 & 180 & 1,5 & 42,0 & 8 & 9 & 34 & 1,4 \\
\hline
\end{tabular}

TABELA N. XIX - Característica da pasta mecânica do bambu do Estado do Acre a 80 ○SR.

\begin{tabular}{|c|c|c|c|c|c|c|c|c|c|}
\hline Essência & $\begin{array}{c}\text { Auto- } \\
\text { ruptura } \\
\text { m }\end{array}$ & $\begin{array}{c}\text { Rasgo } \mathrm{g} \\
\text { por } \\
100 \mathrm{~g} / \mathrm{m}^{2}\end{array}$ & $\begin{array}{c}\text { Estouro } \\
\mathrm{Kg} / \mathrm{cm}^{2} \\
100 \mathrm{~g} / \mathrm{m}^{2}\end{array}$ & $\begin{array}{c}\text { Dobras } \\
\text { duplas } \\
\text { N. }\end{array}$ & $\begin{array}{l}\text { Porosidade } \\
\text { Seg/100c.c. }\end{array}$ & $\begin{array}{c}\text { Lisura } \\
\text { Seg/ } \\
\text { 50c.c. }\end{array}$ & $\begin{array}{c}\text { Maciez } \\
\text { Seg/100c.c. }\end{array}$ & $\begin{array}{c}\text { Alonga- } \\
\text { mento } \\
\%\end{array}$ & $\begin{array}{c}\text { Photovolt } \\
\text { alvura da } \\
\text { pasta }\end{array}$ \\
\hline $\begin{array}{l}\text { Bambu } \\
\text { (essência } \\
\text { verde) }\end{array}$ & 1.044 & 23 & 0,0 & 0,0 & 2 & 5 & 41 & 0,3 & 55 \\
\hline
\end{tabular}

Fabricação de pasta mecânica

Para o estudo de pasta mecânica, as hastes do bambu foram transformadas em palitos, obtendo-se cerca de $200 \mathrm{~g}$ de material por ensaio realizado. Em seguida os palitos foram submersos em água por um período de 12 horas e submetidos a teste de fabricação em desfibrador Sprout Waldron, Mod. D2-202, potência de desfibragem de $40 \mathrm{CV}$, disco $n:$ 17.804. Inicialmente o equipamento operou com os discos afastados de 30 unidades de polegadas para se obter a madeira parcialmente triturada.

Posteriormente, na obtenção das pastas 0 afastamento dos discos foi da ordem de 5 unidades de polegadas. Com o mesmo afastamento procedeu-se o refino da pasta a uma consistência de $2,5 \%$, com passagem suces- siva até a obtenção de um ${ }^{\circ} \mathrm{SR}$ superior a 50 . Obteve-se folhas-de-ensaio com gramatura aproximada de $100 \mathrm{~g} / \mathrm{m}^{2}$ para avaliação das características mecânicas.

Os resultados estão na Tabela $n .^{\circ} \mathrm{XIX}$.

Como se verifica, com exceção do fator rasgo, cuja resistência apresentou a nivel razoável, as demais podem ser consideradas medíocres, quando comparadas com as madeiras tradicionalmente utilizadas na obtençăo de pasta triturada. Se eventualmente os bambus do Estado do Acre vierem a ser utilizados na obtenção de pasta mecânica, haverá necessidade de se incorporar à pasta fabricada uma percentagem de celulose de fibra longa, de coníferas, para melhorar as suas características mecânicas. 


\section{POTENCIALIDADE DE UTILIZAÇĀO DO BAMBU}

Considerando os ensaios realizados e sabendo-se que uma área aproximada de 4.250.000 ha poderia ser constituída essencialmente de bambus, em decorrência da associação desta gramínea com a floresta tropical variar de $20 \%$ a $80 \%$, para um total de 8.500.000 ha, calculou-se a potencialidade de utilização desta matéria-prima, simulando unidade de produção que venham a produzir pasta química alvejada, pastas semiquímicas ou pastas mecano-químicas com capacidade de produção hipotética 100,500 e 1.000 toneladas/dia.

Para efetivação dos cálculos, levou-se em consideração os seguintes fatores:

a) Rendimento: $40 \%$ para as pastas químicas alvejadas, $42 \%$ para as pastas semiquímicas N.S.S.C. e $48 \%$ para as pastas alcalinas mecano-químicas.

b) Dias de fabricação: 350 .

c) Rendimento do bambu (ton/hectare). Tomou-se a média da indústria indiana 1,8 ton/hectare (Tissot, 1970).

Os resultados dos cálculos são mostrados no Quadro n. IV.

QUADRO N.・ IV - Potencialidade de utilização da floresta monovegetal dos bambus (8.500.000 ha)

\begin{tabular}{|c|c|c|c|}
\hline Eepecificaşä॰ & $\begin{array}{l}\text { Copocida- } \\
\text { de de } \\
\text { produçáo } \\
\text { t/dia }\end{array}$ & $\begin{array}{l}\text { Área de } \\
\text { exploroçăo } \\
\text { necessária } \\
\text { ha/ano }\end{array}$ & $\begin{array}{l}\text { Tempo de } \\
\text { suprimen- } \\
\text { to-ano }\end{array}$ \\
\hline \multirow[t]{3}{*}{$\begin{array}{l}\text { Pasta química alve- } \\
\text { jada }\end{array}$} & 100 & 50.000 & 85 \\
\hline & 500 & 250.000 & 17 \\
\hline & 1000 & 500.000 & 8 \\
\hline \multirow{4}{*}{$\begin{array}{l}\text { Pasta semiquímica } \\
\text { N.S.S.C. }\end{array}$} & & & \\
\hline & 100 & 46.000 & 92 \\
\hline & 500 & 232.000 & 18 \\
\hline & 1000 & 463.000 & 9 \\
\hline \multirow{3}{*}{$\begin{array}{l}\text { Pasta alcalina meca- } \\
\text { no-química }\end{array}$} & 100 & 41.000 & 103 \\
\hline & 500 & 203.000 & 20 \\
\hline & 1000 & 406.000 & 10 \\
\hline
\end{tabular}

Como se observa, a floresta monovegetal dos bambus do Acre tem condições de explotabilidade para assegurar o suprimento de futuras fábricas de pastas que venham localizar-se nessa região.

\section{Conclusão}

Considerando o potencial da área coberta $\mathrm{e}$ os resultados dos ensaios realizados, pode-se concluir que os bambus do Estado do Acre são factíveis de serem utilizados na fabricação de pasta e papel, especialmente em unidades de produção que venham utilizar esta matéria-prima na obtenção de pasta de alto rendimento, destinado a manufatura de papéis de embalagem, constituindo assim fonte de atração para investimento naquela região.

\section{SUMMARY}

Samples from Bamboo of the Acre Region were studied from the pulp and paper stand point. Short informations about the geographical distribution of this gramineous plant and its utilization in the pulp and paper industry principally in the asiatic mainland are given. General characteristics about required soil climate and relief so are evident. The valuations about the density, classification and micrometry of the fiber, qualities of the chemical, semichemical, chemimechanical and mechanical pulps, as well as the results of the bleaching, semibleaching and the rough calculation of the potencial utilization are showed. It fallows that Acre's Bamboos are feasible to make pulp and paper, principally in the manufacture of the paperboard.

\section{BIBLIOGRAFIA CITADA}

\section{Associação paulista dos fabricantes de Papel B Celulose \\ 1975 - Relatório Estatístico (Mımiografado) 1-186.}

AZZINI, A.

1976 - Influência das dimensões dos cavacos de Bambusa vulgaris schrad no rendimento, percentagem de rejeitos, número kappa e alvura da celulose obtida pejo processo sulfato. O Papel, São Paulo, 37 : 125-137, dezembro. 
Brasil. MtNistério das minas e Energia, Projeto RADAM.

1976 - Levantamento de Recursos Naturais. V. - 10 - Folha S.A 21 -Santarém, Geologia, Geomorfologia, Vegetação Uso Potencial da Terra. Rio de Janeiro, p. 29.

Brasil. MINISTÉrio das MINAS E ENERgia

1977 - PROJETO RADAM (Mimiografado).

BRECHT, W.

1967 - A method for comparative evoluation of bar equipped beating devices. TAPPI - Technical Association of the Pulp and Paper Industry, Atlanta, 50(8): 40A-44A.

Clark V. d'A.

1962 - Effects of Fiber coarsenss and lenth. I - Bulk, Burst, Fold and Tensive Tests TAPPI, (8) : 45 .

CORRÊA, A.A. \& LUZ, C.N.R.

1976 - Essência Papeleira de Reflorestamento II - O Pinus caribeae (variedade hondurensis) introduzido na Amazônia. Acta Amazonica, Manaus, 6(1): 75-98.

DOAT, J.

1967 - Les Bambus, Source Eventuelle de Cellulose pour L'Afrique. Bois et Forêts des Tropiques, Nogent-sur-Marne, (113): 41.59.

HUBERMaN, M.A.

1959 - La Silvicultura del Bambú. Unasylva, Roma, 13(1):36-43.

LE CONNT, $\boldsymbol{P}$.

1947 - Amazônia Brasileira. III. Árvores e Plantas Uteis (indigenas e aclimatadas), nomes vernáculos e nomes vulgares. Classificação botânica, habitat, principais aplicações e propriedades. 2." ed São Paulo, Companhia Editora Nacional. p. $443,444,455$.

Mazzei, F.M. \& OVerbeck, W.

1966 - Investigação da influência da idade nos característicos físicos e químicos do lenho e das plantas celulósicas de Euca lyptus saligna. Publicação do Instituto de Pesquisas Tecnológicas, São Paulo, (758) : 1-29.

MAZZEI, F.M. \& REDKo, B.V.P.

1967 - Celulose para papel a partir do Bambu. Publicação do Instituto de Pesquisas Tecnológicas, São Paulo (796): 1-7.

REDKo, B.V.P. \& Nishimura, M.

1972 - Celulose de Bambu. O Papel, (33) : $38-44$, abril.

TissoT, $\mathbf{M}$.

1970 - Le bambou, matière première pour l'industrie papetière indienne. Bois et Forêts des Tropiques, Nogent-sur. -Marne, (129) : 21-45.

WAYMAN, M

1973 - Informacion tecnica sobre materias primas y fabricacion de pasta $y$ papel in guia para planificar empresas $y$ fabricas de pasta y papel - organizacion de las naciones unidas para la agricultura y la alimentacion. Roma p. $275-290$. 


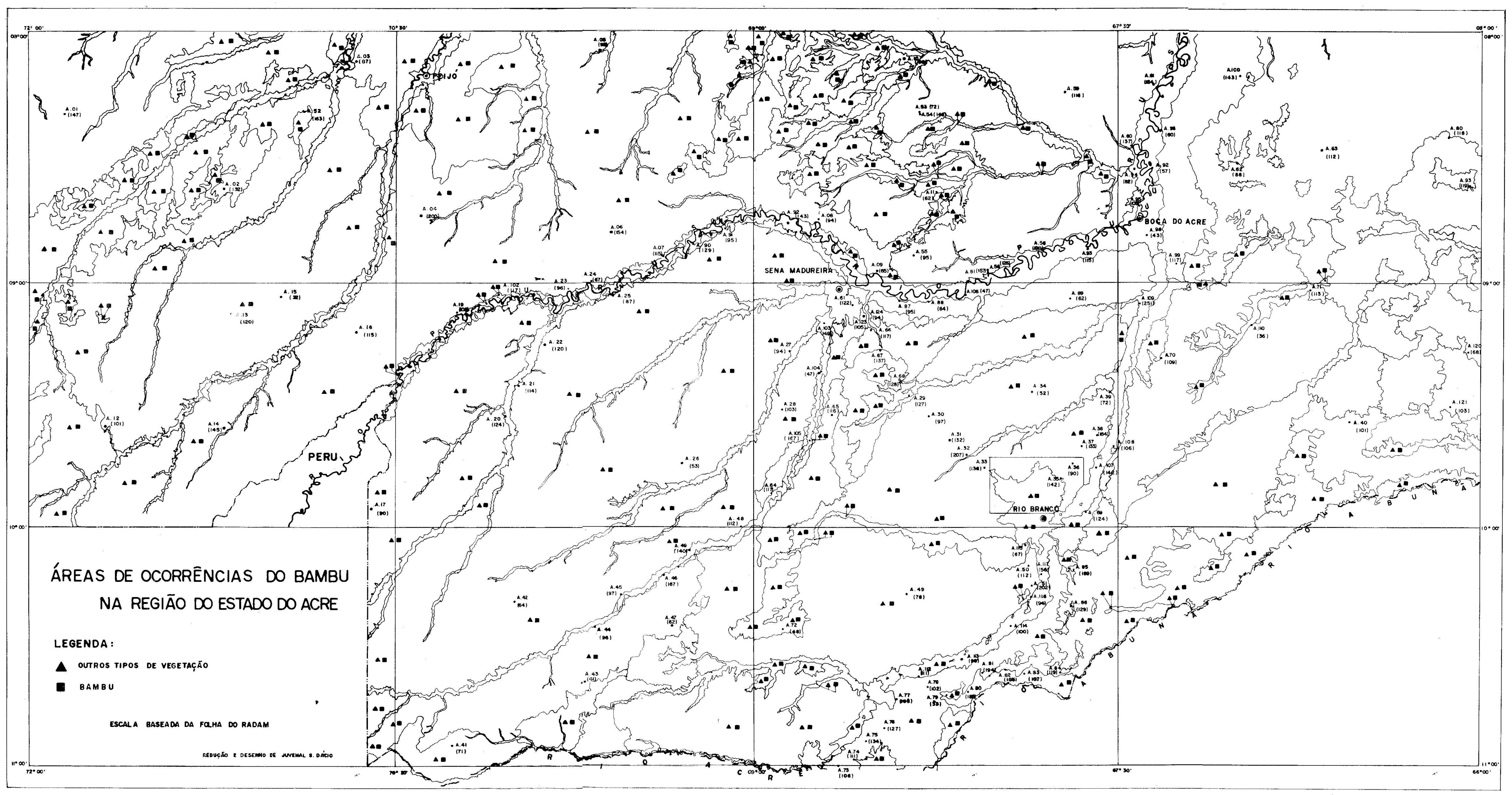

